\title{
Bulk and Interfacial Properties of the
}

\section{Decane+Water System in the Presence of Methane, Carbon Dioxide, and Their Mixture}

\author{
Yafan Yang, Arun Kumar Narayanan Nair, \\ Mohd Fuad Anwari Che Ruslan, and Shuyu Sun ${ }^{\dagger}$ \\ Physical Science and Engineering Division (PSE), \\ Computational Transport Phenomena Laboratory, \\ King Abdullah University of Science and Technology (KAUST), \\ Thuwal, 23955-6900, Saudi Arabia.
}

October 7, 2020

\footnotetext{
${ }^{*}$ To whom correspondence should be addressed, email: arun.narayanannair@kaust.edu.sa

†To whom correspondence should be addressed, email: shuyu.sun@kaust.edu.sa
} 


\begin{abstract}
Molecular dynamics simulations are carried out to study the two-phase behavior of the n-decane+water system in the presence of methane, carbon dioxide, and their mixture at reservoir conditions. The simulation studies were complemented by theoretical modeling using the perturbed-chain statistical associating fluid theory (PC-SAFT) equation of state (EoS) and density gradient theory. Our results show that the presence of methane and carbon dioxide decreases the interfacial tension (IFT) of the decane+water system. In general, the IFT increases with increasing pressure and decreasing temperature for the methane+decane+water and carbon dioxide+decane+water systems, similar to what has been found for the corresponding decane+water system. The most important finding of this study is that the presence of carbon dioxide decreases the IFT of the methane+decane+water system. The atomic density profiles provide evidence of the local accumulation of methane and carbon dioxide at the interface, in most of the studied systems. The results of this study show the preferential dissolution in the water-rich phase and enrichment at the interface for carbon dioxide in the methane+carbon dioxide+decane+water system. This indicates the preferential interaction of water with carbon dioxide relative to methane and decane. Notably, there is an enrichment of the interface by decane at high mole fractions of methane in the methane/decane-rich or methane/carbon dioxide/decane-rich phase. Overall, the solubility of methane and carbon dioxide in the water-rich phase increases with increasing pressure and temperature. Additionally, we find that the overall performance of the PC-SAFT EoS and the cubic-plus-association EoS is similar with respect to the calculation of bulk and interfacial properties of these systems.
\end{abstract}




\section{Introduction}

Currently, more than $30 \mathrm{Gt}$ of anthropogenic carbon dioxide is emitted per year, mainly from the combustion of fossil fuels. ${ }^{1}$ The emission of carbon dioxide into the atmosphere plays a key role in global warming and leads to important environmental problems. ${ }^{2-5}$ For instance, the melting of ice sheets and glaciers due to global warming likely contributes to sea level rise. Notably, carbon capture and storage (CCS) is regarded as an important technology for the reduction of anthropogenic carbon dioxide emissions. Many materials such as zeolites, ${ }^{6,7}$ metal-organic frameworks, ${ }^{7,8}$ polymers, ${ }^{6,9-11}$ and geological formations ${ }^{12-22}$ have been used for CCS.

Interestingly, enhanced oil recovery (EOR) techniques have been considered for sequestering carbon dioxide and improving oil recovery. ${ }^{15-22}$ In $2015, \mathrm{CO}_{2}$-EOR delivered approximately $3 \%$ of the U.S. crude oil supply and its involvement will continue to grow in the coming decades. ${ }^{22}$ Currently, the water-alternating-gas (WAG) method has been used in the $\mathrm{CO}_{2}$-EOR projects to reduce the unfavorable mobility of carbon dioxide in the formations. ${ }^{20,21}$ During the WAG process, water is injected alternately with carbon dioxide for mobility control. Therefore, bulk and interfacial properties of the $\mathrm{CO}_{2}+$ oil +water system play an important role in the $\mathrm{CO}_{2}$-EOR projects. For instance, the oil recovery efficiency can be correlated to the interfacial tension (IFT) using the capillary number defined as the ratio of the viscous forces to capillary forces. ${ }^{18}$ The capillary number increases as IFT decreases and/or viscosity increases. A lower IFT is desirable for the $\mathrm{CO}_{2}$-EOR techniques which may help to improve oil recovery. Traditionally in the U.S, carbon dioxide from natural sources were employed for approximately $90 \%$ of $\mathrm{CO}_{2}$-EOR supply. ${ }^{19}$ Whereas, $\mathrm{CO}_{2}$-EOR utilizing anthropogenic emissions would be required to obtain the desired environmental benefits. Notably, impurities are present in the carbon dioxide stream obtained from industrial and power sectors. ${ }^{23-25}$ In general, techniques used for the removal of impurities from the gas streams are expensive. Thus, it is significant to investigate the properties of the $\mathrm{CO}_{2}$ +oil+water system in the presence of impurities such as $\mathrm{CH}_{4}$ for improving 
the performance of CCS and EOR.

Many experimental, ${ }^{26-36}$ theoretical, ${ }^{26,30-32,35}$ and simulation ${ }^{37-41}$ works have been done to obtain the bulk and interfacial properties of ternary mixtures of $\mathrm{CH}_{4}$ or $\mathrm{CO}_{2}$ with water and alkanes (e.g., n-decane which is the model oil in this study) at reservoir conditions. In these studies, large regions of two- and three-phase equilibria were observed for such ternary systems, and the three-phase region decreased with increasing pressure. Furthermore, it was shown that the IFT of, for instance, the decane+water system generally decreases in the presence of $\mathrm{CH}_{4}$ and $\mathrm{CO}_{2} \cdot{ }^{26-28}$ This

can be attributed to the local enrichment of the interface by $\mathrm{CH}_{4}$ and $\mathrm{CO}_{2} \cdot{ }^{37-41}$ Also the IFT generally increases with increasing pressure and decreasing temperature for the $\mathrm{CH}_{4}$ +decane+water and $\mathrm{CO}_{2}$ +decane+water systems in the two-phase region. ${ }^{26-28}$ Notably, the study of quaternary mixtures containing $\mathrm{CH}_{4}, \mathrm{CO}_{2}$, water, and higher alkanes has not been reported so far.

Molecular simulations give important insights into the interfacial and bulk environments of different systems. ${ }^{11-14,42-49}$ In this study, molecular dynamics (MD) simulations were carried out to understand the properties of $\mathrm{CH}_{4}+$ decane+water, $\mathrm{CO}_{2}$ +decane+water, and $\mathrm{CH}_{4}+\mathrm{CO}_{2}$ +decane+water systems at reservoir conditions. The simulation studies were complemented by theoretical modeling because of the general lack of experimental data for such systems, especially the quaternary case.

\section{Simulation details}

MD simulations were carried out utilizing the LAMMPS code ${ }^{50}$ to study the two-phase behavior of the n-decane+water system in the presence of $\mathrm{CH}_{4}, \mathrm{CO}_{2}$, and their mixture over broad ranges of temperature (323-443 K) and pressure (up to about $100 \mathrm{MPa}$ ). The simulation models and methods implemented here were the same as described in our previous studies. ${ }^{47,48}$ Additionally, the transferable potentials for phase equilibria $(\text { TraPPE })^{51}$ united atom force field is employed to model the n-decane molecules and the Lennard-Jones (LJ) parameter for unlike atoms $\varepsilon_{i j}$ is estimated using an extended 
version $^{52}$ of the Lorentz-Berthelot combining rule:

$$
\varepsilon_{i j}=k_{i j}^{\mathrm{LJ}} \sqrt{\varepsilon_{i} \varepsilon_{j}}
$$

where $k_{i j}^{\mathrm{LJ}}$ is an adjustable parameter. In our simulations, the parameter $k_{i j}^{\mathrm{LJ}}=1$, unless otherwise stated. Each simulation box contained 2048 water molecules and up to $625 \mathrm{CH}_{4} / \mathrm{CO}_{2} /$ decane molecules (Fig. 1 and Table 1 ). In all cases, the box dimensions parallel to the interface were about $36 \times 36 \AA$. The MD runs are carried out with periodic boundary conditions in all three dimensions. The box dimensions are sufficiently large so that the finite-size effects are negligible in the estimations of the bulk and interfacial properties. ${ }^{47,53}$ Each system is subjected to 5 ns equilibration run in the NPT ensemble followed by 5 ns production run in the $N V E$ ensemble. Only the box size in the $z$ direction (normal to the interface) was allowed to vary during the NPT simulations. We have employed a velocity Verlet algorithm with a constant step size of 1 fs to integrate the equations of motion. The Nosé-Hoover thermostat with a relaxation time of 0.1 ps and the Nosé-Hoover barostat with a relaxation time of 1.0 ps are employed to control the temperature and pressure, respectively. The long-range electrostatic interactions were evaluated by the particle-particle particle-mesh method with a precision of $10^{-5}$. We chose a cutoff of $15 \AA$ for both LJ and electrostatic interactions. The error bars are based on the standard deviation of the mean of four independent MD trajectories.

The IFT is evaluated as follows: ${ }^{47-49,53,54}$

$$
\gamma=\frac{1}{2} L_{z}\left[P_{z z}-\frac{1}{2}\left(P_{x x}+P_{y y}\right)\right]
$$

where $L_{z}$ denotes the box size in the $z$ direction, and $P_{x x}, P_{y y}$, and $P_{z z}$ represent the three diagonal components of the pressure tensor. The components of the pressure tensor are calculated using the virial route as implemented in LAMMPS. ${ }^{50} \mathrm{~A}$ better agreement between simulation and experimental results was found by tuning the $k_{i j}^{\mathrm{LJ}}$ parameter (see eq. (1), and Figures S1 and S2). In this study, we chose $k_{i j}^{\mathrm{LJ}}=1.1$ for 


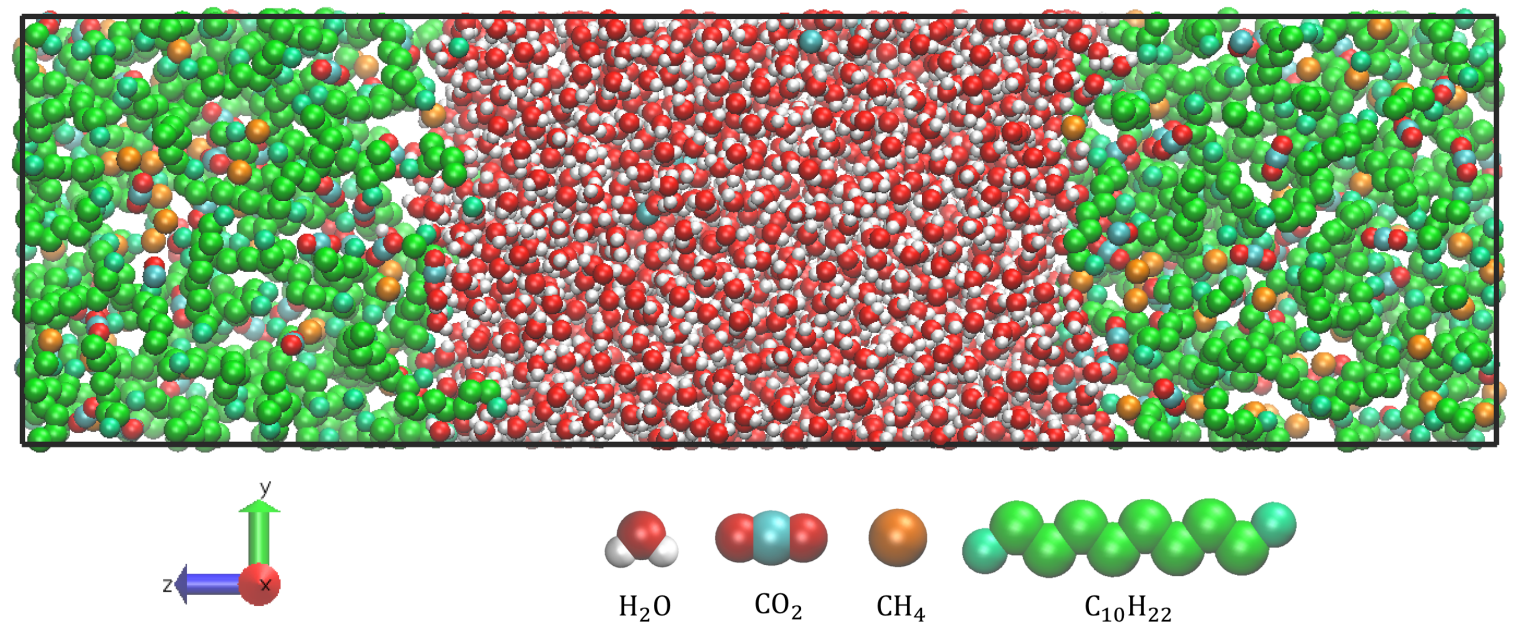

Figure 1: Equilibrium snapshot of the $\mathrm{CH}_{4}+\mathrm{CO}_{2}+$ n-decane system $\left(x_{\mathrm{CH}_{4}}=x_{\mathrm{CO}_{2}} \approx\right.$ $0.25)$ at $443 \mathrm{~K}$ and $30 \mathrm{MPa}$.

both water $(\mathrm{O})$-carbon dioxide $(\mathrm{C})$ and water $(\mathrm{O})$-decane pairs.

\section{Theoretical details}

The familiar perturbed-chain statistical associating fluid theory (PC-SAFT) equation of state (EoS) was employed to calculate bulk properties (e.g., solubility) of the system. More details of the PC-SAFT EoS can be found elsewhere. ${ }^{55,56}$ In brief, the PC-SAFT EoS can by expressed via the compressibility factor $Z$ :

$$
Z=1+Z^{\mathrm{hc}}+Z^{\mathrm{disp}}+Z^{\mathrm{assoc}}
$$

where $Z^{\text {hc }}$ is the hard-chain term, $Z^{\text {disp }}$ is the dispersive part, and $Z^{\text {assoc }}$ represents the contribution due to association. Water is modeled using the $4 \mathrm{C}$ association scheme ${ }^{57}$ and $\mathrm{CO}_{2}$ is allowed to cross-associate with $\mathrm{H}_{2} \mathrm{O}$ (solvation). ${ }^{58}$ The PC-SAFT EoS parameters used in this study are given in Tables S1 and S2. These parameters were obtained from literature ${ }^{55,59}$ and in the absence of literature data, they were regressed from the experimental data. ${ }^{60-63}$

In addition, the PC-SAFT EoS was coupled with the density gradient theory (DGT) 
for the estimation of the interfacial properties. Briefly, for a planar interface of area $A$, the Helmholtz free energy is given as ${ }^{64,65}$

$$
F=A \int_{-\infty}^{+\infty}\left[f_{0}(n)+\frac{1}{2} \sum_{i} \sum_{j} c_{i j} \frac{d n_{i}}{d z} \frac{d n_{j}}{d z}\right] d z
$$

where $f_{0}$ denotes the Helmholtz free energy density of the homogeneous fluid at the local density $n, d n_{i} / d z$ represents the local density gradient of the $i$ th component. The cross influence parameter $c_{i j}$ is defined as

$$
c_{i j}=\left(1-\beta_{i j}\right) \sqrt{c_{i i} c_{j j}}
$$

where $c_{i i}$ and $c_{j j}$ represent the pure component influence parameters, and $\beta_{i j}$ denote the binary interaction coefficient. The pure component influence parameters and the binary interaction coefficients used in this study are given in Tables S3 and S4. These parameters were obtained from literature ${ }^{66}$ and in the absence of literature data, they were identified by fitting the experimental data. ${ }^{27,67-69}$

In equilibrium, the density profiles across the interface is evaluated through the minimization of the free energy by solving the corresponding Euler-Lagrange equation:

$$
\sum_{j} c_{i j} \frac{d^{2} n_{j}}{d z^{2}}=\mu_{i}^{0}\left(n_{1}(z), \ldots, n_{N_{c}}(z)\right)-\mu_{i} \text { for } i, j=1, . ., N_{c}
$$

where $\mu_{i}^{0} \equiv\left(\frac{\partial f_{0}}{\partial n_{i}}\right)_{T, V, n_{j}}, \mu_{i}$ represents the chemical potential of the $i$ th component and $N_{c}$ denotes the total number of components. These equations were solved together with the Dirichlet boundary conditions:

$$
\begin{aligned}
& n_{i}=n_{i}^{I} \text { at } z=0 \\
& n_{i}=n_{i}^{I I} \text { at } z=l,
\end{aligned}
$$

where $n_{i}^{I}$ and $n_{i}^{I I}$ represent the bulk densities of the coexisting phases and $l$ denotes the 


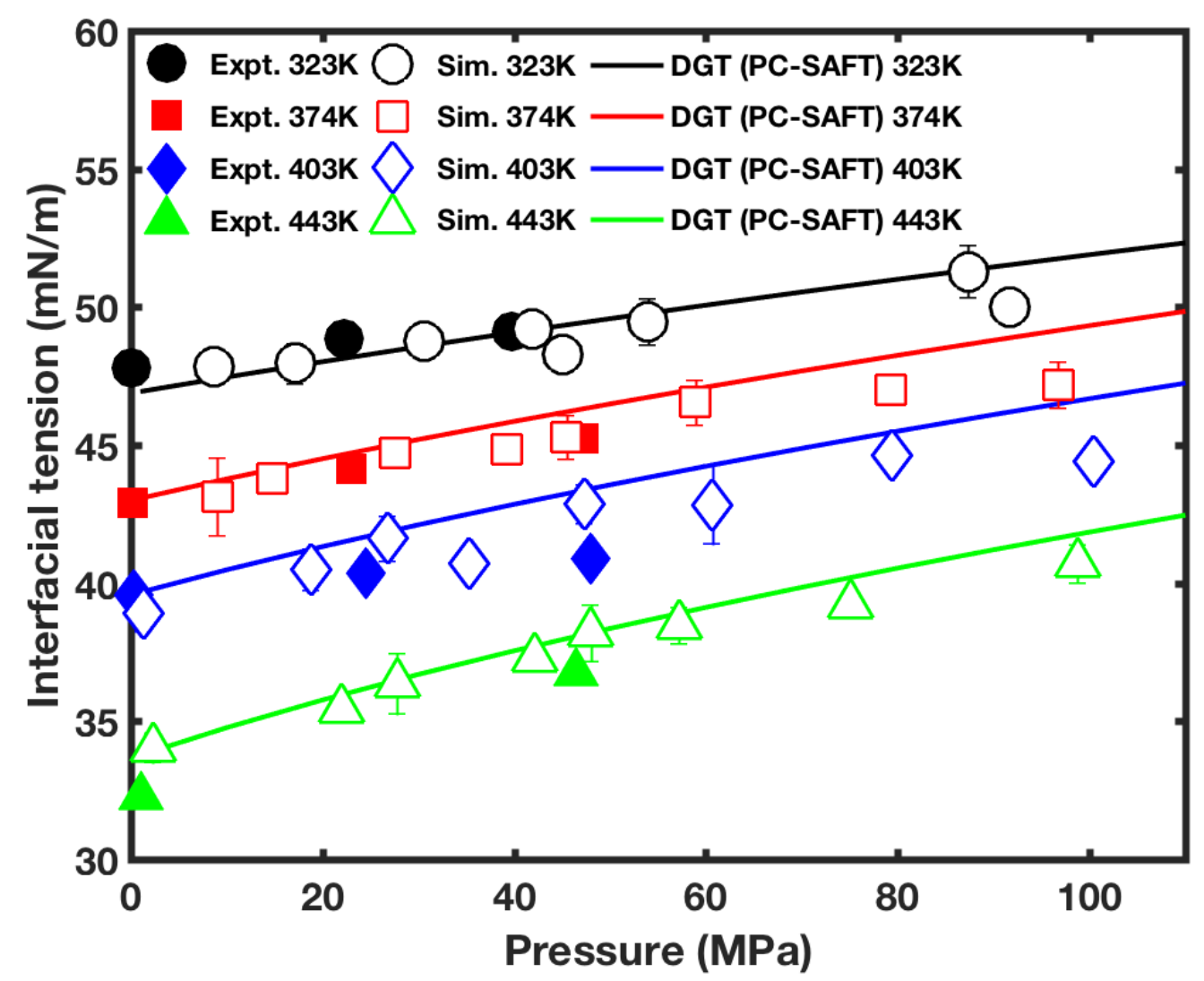

Figure 2: Interfacial tension as a function of pressure for the decane+water system. The open symbols represent the results from the MD simulations and the estimates obtained using DGT with the PC-SAFT EoS are shown as lines. The experimental results of Georgiadis et al. ${ }^{27}$ are shown as solid symbols.

interfacial thickness. The bulk properties are calculated employing the PC-SAFT EoS as described above. Once the equilibrium density profiles are available, the interfacial tension $\gamma$ is estimated as follows:

$$
\gamma=\int_{-\infty}^{+\infty} \sum_{i} \sum_{j} c_{i j} \frac{d n_{i}}{d z} \frac{d n_{j}}{d z} d z
$$




\section{Results and discussion}

\subsection{Decane+water system}

Fig. 2 provides the IFT of the decane+water system obtained using MD (open symbols) and theoretical (lines) calculations. Our results are also compared with the corresponding experimental ${ }^{27}$ quantities (solid symbols). Other experimental results ${ }^{70-74}$ agree with the ones reported here and are omitted for clarity. It is seen that our simulation and theoretical results are consistent with the experimental observations. The overall absolute average deviation, for instance, between the experimental and theoretical IFT data was less than about 2.3\%. From these results it is clear that the IFT almost linearly increases with increasing pressure. We find that the linear slope of the IFT versus pressure plot increases with increasing temperature. For instance, the simulated slope changes from about $0.03 \mathrm{mN} /(\mathrm{m} \mathrm{MPa})$ at $323 \mathrm{~K}$ to $0.07 \mathrm{mN} /(\mathrm{m} \mathrm{MPa})$ at $443 \mathrm{~K}$. Also, for a given pressure, the IFT decreases almost linearly with increasing temperature. For instance, the slope changes from about -0.10 to $-0.07 \mathrm{mN} /(\mathrm{m} \mathrm{K})$ in the pressure range 30-100 MPa (Figure S3). These results are consistent with other theoretical $^{75-77}$ and simulation ${ }^{52,78-80}$ studies.

The atomic density profiles can be readily obtained using molecular simulations and/or DGT, in comparison to experiments. For instance, Figure S4 provides the density profiles of water and decane as predicted by MD (solid lines) and theoretical (dashed lines) calculations for the decane+water system. An overall agreement between the simulation and theoretical results has been obtained. The theory shows that the density profiles of water and decane vary monotonically across the interface. Notably, in contrast to the theoretical prediction, there are oscillations present near the interface for the simulated density profile of decane at low temperatures. This may be due to the finite size of the simulated system. ${ }^{81,82}$ These density profiles of water and decane can also be described approximately by a hyperbolic tangent function. ${ }^{81}$ Furthermore, we see that the estimated water and decane liquid densities (Figure S5) away from the interface are in good agreement with the corresponding experimental liquid densities 
of pure cases. ${ }^{67}$ These results show that decane is less dense than water, and the densities of both water and decane increase with increasing pressure and decreasing temperature. Such agreement indicates the low mutual solubility of water and decane under the studied conditions. For example, Figure S6 shows our calculated solubilities of water and decane at $0.1 \mathrm{MPa}$ and the corresponding experimental data. ${ }^{60} \mathrm{~A}$ good quantitative agreement is obtained between the theoretical and experimental data. However, the simulated solubility values, for example, of water in the decane-rich phase differ by about an order of magnitude from the experimental data. A similar finding was reported for the water solubility in other alkanes. ${ }^{52}$ The agreement between the experimental and simulated solubility data may be improved by using, e.g., the TIP4P water model with the TraPPE united atom model for alkanes. ${ }^{52}$ Notably, the simulation of the IFT using the TIP4P/2005 water model performs better than that with most of the frequently employed water models. ${ }^{47,52}$

The IFT can be understood in detail by means of the surface excess $\Gamma_{i}$ and the relation is given by the Gibbs adsorption equation: ${ }^{48,49,53,69}$

$$
-d \gamma=\sum_{i} \Gamma_{i} d \mu_{i}
$$

The surface excess of the $i$ th component relative to water is expressed as

$$
\Gamma_{i, \text { water }}=-\alpha_{i} \int_{-\infty}^{+\infty} \Delta C(z) d z
$$

with

$$
\Delta C(z)=\frac{n_{\text {water }}(z)-n_{\text {water }}^{I I}}{\alpha_{\text {water }}}-\frac{n_{i}(z)-n_{i}^{I I}}{\alpha_{i}}
$$

where

$$
\alpha_{i}=\frac{n_{i}^{I I}-n_{i}^{I}}{n_{i}^{I I}-n_{i}^{I}+n_{\mathrm{water}}^{I I}-n_{\mathrm{water}}^{I}}
$$


and

$$
\alpha_{\mathrm{water}}=\frac{n_{\mathrm{water}}^{I I}-n_{\mathrm{water}}^{I}}{n_{i}^{I I}-n_{i}^{I}+n_{\mathrm{water}}^{I I}-n_{\mathrm{water}}^{I}} .
$$

Here, $I$ denotes the decane-rich phase and $I I$ represents the water-rich phase. Figure S7 provides the surface excess of decane as calculated from simulations (symbols) and from theoretical modeling (solid lines) for the decane+water system. We see that our simulation results are qualitatively consistent with the theoretical calculations. The maximum deviation (about a factor of 2) between the simulated surface excess values and the theoretical ones is found at the lowest studied temperature and at high pressures. We observe a negative surface excess for decane, which explains the increase in the IFT with pressure (see, e.g., eq. (9) and Fig. 2). We also notice that, at a given pressure, the surface excess of decane decreases with increasing temperature. This can explain the fact that the slope of the IFT versus pressure plot increases with increasing temperature. The negative surface excess of decane is expected because of the effects of the unfavorable hydrophobic-hydrophilic interaction between decane and water. ${ }^{78,80}$

\subsection{Decane+water system in the presence of $\mathrm{CH}_{4}$}

Fig. 3 provides the IFTs as obtained from the MD calculations (open symbols) and the corresponding theoretical results (lines) for the decane+water system in the presence of methane (mole fraction of methane in the decane/ $\mathrm{CH}_{4}$-rich phase $x_{\mathrm{CH}_{4}} \approx 0.2,0.5$, and 0.8) under geological conditions. The simulated IFT values at different pressures were replotted as a function of temperature and mole fraction of methane $x_{\mathrm{CH}_{4}}$ in Figures S8 and S9, respectively. It is seen that our simulation results are consistent with the theoretical predictions. Note that our results are in qualitative agreement with the only available experimental ${ }^{28}$ data (solid symbols). The difference may be due to, for example, the force-field model employed in our simulations. As in the case of the decane+water system, the IFT almost linearly increases with pressure and the linear slope of the IFT versus pressure plot increases with temperature for the methane+decane+water system. Also, the linear slope of the IFT versus pressure plot 

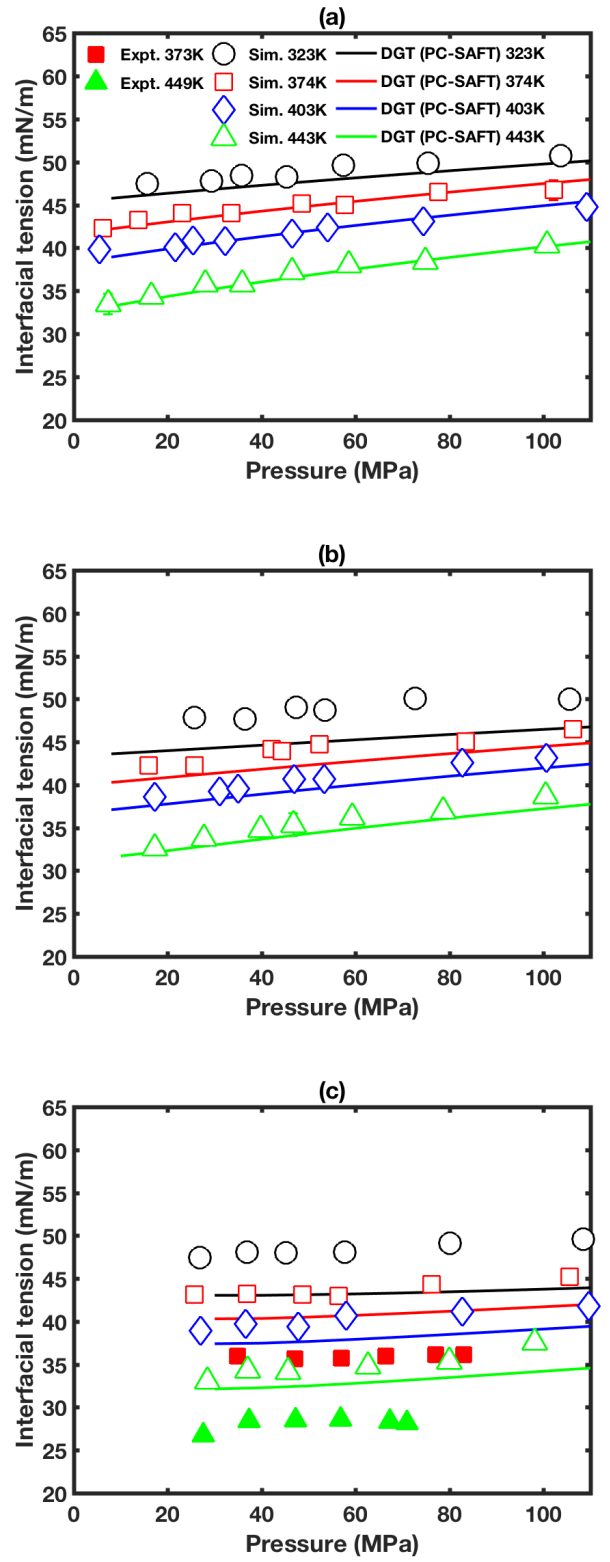

Figure 3: Interfacial tension as a function of pressure for the $\mathrm{CH}_{4}$ +decane+water system with (a) $x_{\mathrm{CH}_{4}} \approx 0.2$, (b) $x_{\mathrm{CH}_{4}} \approx 0.5$, and (c) $x_{\mathrm{CH}_{4}} \approx 0.8$. The open symbols represent the results from the MD simulations and the estimates obtained using DGT with the PC-SAFT EoS are shown as lines. The experimental results of Jennings and Newman ${ }^{28}$ are shown as solid symbols. 
(a)

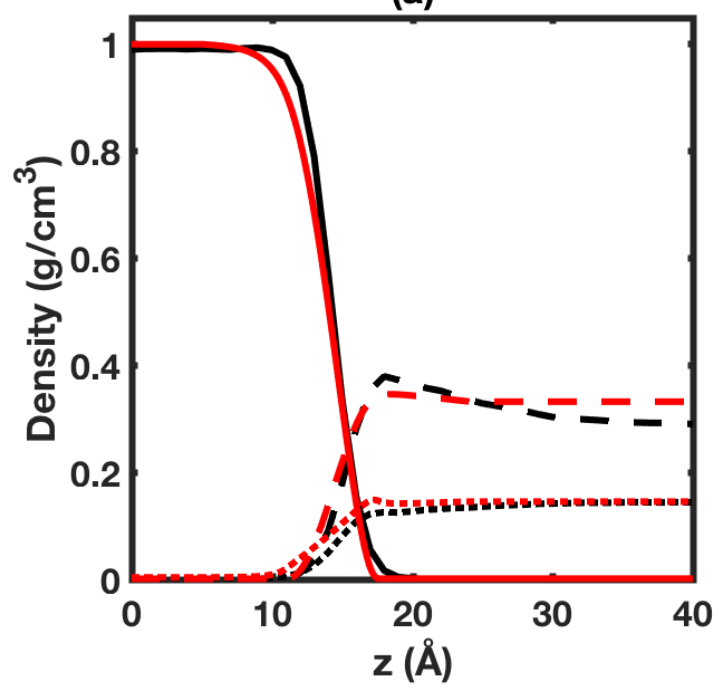

(c)

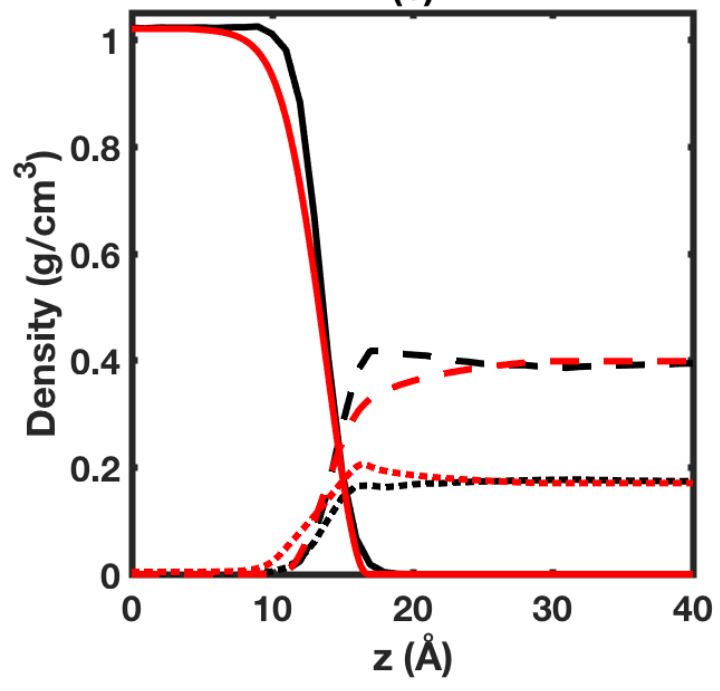

(b)

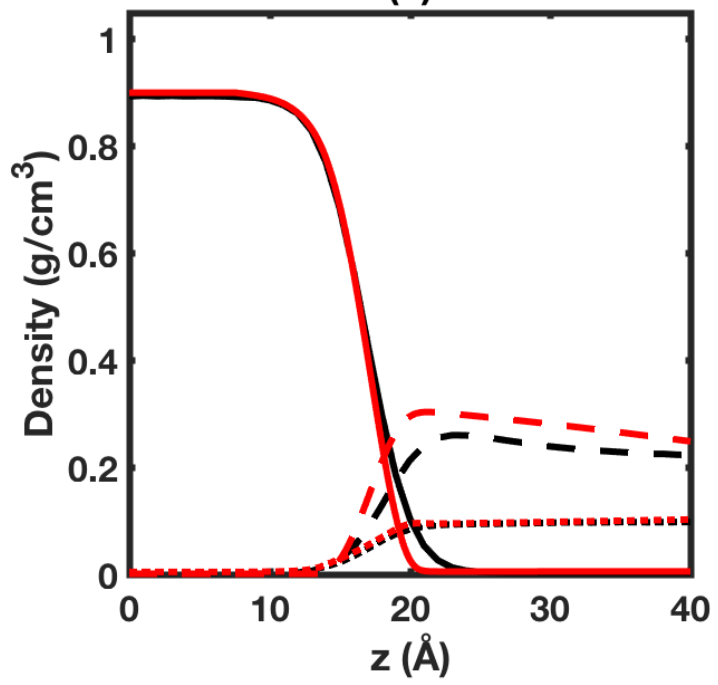

(d)

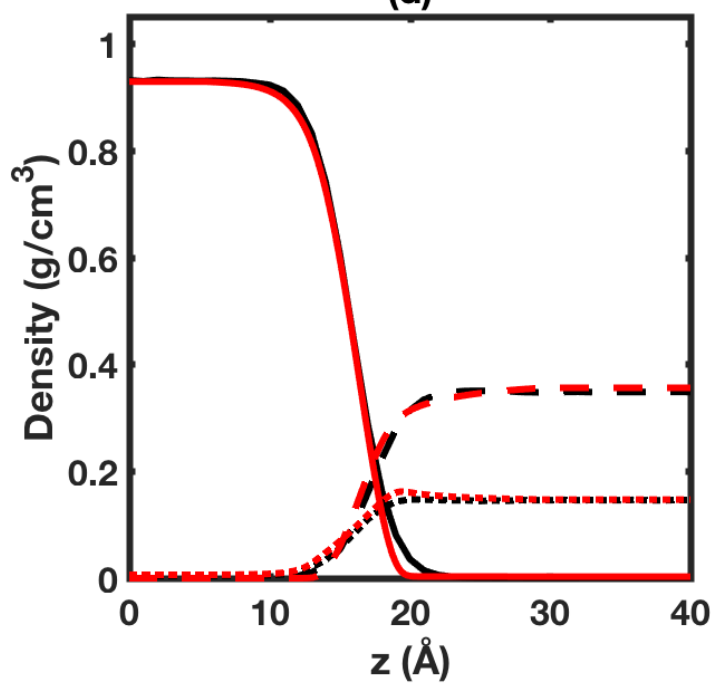

Figure 4: Equilibrium distributions of different species in the $\mathrm{CH}_{4}+$ decane+water system $\left(x_{\mathrm{CH}_{4}} \approx 0.8\right.$ ) at (a) $323 \mathrm{~K}$ and $30 \mathrm{MPa}$, (b) $443 \mathrm{~K}$ and $30 \mathrm{MPa}$, (c) $323 \mathrm{~K}$ and $100 \mathrm{MPa}$, and (d) $443 \mathrm{~K}$ and $100 \mathrm{MPa}$. The black and red colors represent MD simulation and DGT, respectively. The solid, dashed, and dotted lines denote water, decane, and methane, respectively.

decreases with increasing mole fraction of methane $x_{\mathrm{CH}_{4}}$. For instance, the simulated slope $(T=443 \mathrm{~K})$ changes from about $0.07 \mathrm{mN} /(\mathrm{m} \mathrm{MPa})$ at $x_{\mathrm{CH}_{4}} \approx 0.2$ to $0.03 \mathrm{mN} /(\mathrm{m}$ 
MPa) at $x_{\mathrm{CH}_{4}} \approx 0.8$. It is worth noting that, the IFT shows a nonmonotonic dependence on pressure in the methane+water system and, at low pressures, it decreases with pressure as discussed in previous studies. ${ }^{47,69}$ Also, for a given pressure, the IFT generally decreases almost linearly with increasing temperature and increasing mole fraction of methane $x_{\mathrm{CH}_{4}}$. It can be seen that, independent of the mole fraction of methane $x_{\mathrm{CH}_{4}}$, the slope of the IFT versus temperature plot varies from about -0.11 to $-0.08 \mathrm{mN} /(\mathrm{m} \mathrm{K})$ in the pressure range $30-100 \mathrm{MPa}$ (see Figure S8). The slope of the IFT versus mole fraction of methane $x_{\mathrm{CH}_{4}}$ plot is in the range of about -4 to -1 $\mathrm{mN} / \mathrm{m}$ (see Figure S9). Note that these results are consistent with the work of Pereira et al. ${ }^{26}$

It is interesting to explore the atomic density profiles to gain more insights into the bulk and interfacial properties of the methane+decane+water system. For example, Fig. 4 provides the density profiles of methane, decane, and water as predicted by $\mathrm{MD}$ and theoretical calculations for the methane+decane+water system $\left(x_{\mathrm{CH}_{4}} \approx 0.8\right)$. Also, Figures S10 and S11 provide these profiles at $x_{\mathrm{CH}_{4}} \approx 0.2$ and $x_{\mathrm{CH}_{4}} \approx 0.5$, respectively. An overall agreement between the simulation and theoretical results has been obtained. Here the shape of the density profiles of decane and water is, in general, similar to that observed for the decane+water system. An important finding of this study is the enrichment of the interface by decane at high values of $x_{\mathrm{CH}_{4}}$ (see, e.g., Fig. 4). Overall, these effects seem to be more pronounced at low pressures and temperatures. This is consistent with the fact that, $\mathrm{CH}_{4}$ and decane are immiscible at low pressures and temperatures. ${ }^{49}$ The water-water and decane-decane interactions are stronger compared to water-decane interaction and this may result in the negative surface excess of decane at low values of $x_{\mathrm{CH}_{4}}$ (see above). The stronger interaction of a water molecule with a decane molecule than with a $\mathrm{CH}_{4}$ molecule (simulated binding energy of decane-water and $\mathrm{CH}_{4}$-water are about -0.74 and $-0.24 \mathrm{kcal} / \mathrm{mol}$, respectively) may favor the enrichment of decane at the interface at high values of $x_{\mathrm{CH}_{4}}$. Such enrichment is important with regards to the IFT (see, e.g., eq. (9)) and is also believed to influence the diffusion profile and the mass transfer across 
interfaces. ${ }^{27,38,39,68}$ Notably, the density profiles display a systematic adsorption of methane in the interface. We see that this local enrichment of methane at the interface increases with increasing pressure and decreasing temperature. It is worth noting that, the local enrichment of methane shows a nonmonotonic dependence on pressure in the methane+water system as discussed in previous studies. ${ }^{47,69}$ Our results also show that the enrichment of the interface by methane generally increases with increasing mole fraction of methane $x_{\mathrm{CH}_{4}}$. Furthermore, Figures S12, S13, and S14 show our calculated solubilities of $\mathrm{CH}_{4}$ in the water-rich phase, decane in the water-rich phase, and water in the decane $/ \mathrm{CH}_{4}$-rich phase, respectively, under the studied conditions. Our results show that these solubilities are affected by pressure, temperature, and mole fraction of methane $x_{\mathrm{CH}_{4}}$. For example, the solubility of methane increases with pressure, whereas that of decane and water shows an opposite trend. The solubilities of the different species generally increase with temperature. The solubility behavior of decane is consistent with the fact that the density of water-rich phase increases with increasing pressure and decreasing temperature. In general, the solubility of methane increases with increasing mole fraction of methane $x_{\mathrm{CH}_{4}}$, whereas that of decane and water shows an opposite trend.

It is also interesting to explore the surface excess in order to quantify, for example, the local enrichment of methane at the interface. Figures S15 and S16 provide the surface excess of methane and decane, respectively, as calculated from simulations (symbols) and from theoretical modeling (solid lines) for the methane+decane+water system under the studied conditions. We see that our simulation results are qualitatively consistent with the theoretical calculations. In general, we observe a positive surface excess for methane. Our results show that the surface excess of methane increases with increasing pressure and decreasing temperature. Also the surface excess of methane generally increases with increasing mole fraction of methane $x_{\mathrm{CH}_{4}}$. In general, we observe a negative surface excess for decane, similar to case of the decane+water system. The dependence of this surface excess of decane on pressure and temperature is also, in general, similar to the decane+water system. As expected, the surface 
excess of decane generally decreases with increasing mole fraction of methane $x_{\mathrm{CH}_{4}}$. However, we find a positive surface excess for decane at high values of $x_{\mathrm{CH}_{4}}$. These effects seem to be more pronounced at low pressures and temperatures. Also, methane seems to show negative values of surface excess, for example, in this region. As mentioned above, the stronger interaction of a water molecule with a decane molecule than with a $\mathrm{CH}_{4}$ molecule may favor the enrichment (depletion) of decane (methane) at the interface. Note that the simultaneous enrichment of the interface with $\mathrm{CO}_{2}$ and $\mathrm{CH}_{4}$ has been observed. ${ }^{47,48,69}$ However, the relatively high density of decane may not allow the simultaneous enrichment of the interface with decane and $\mathrm{CH}_{4}$ (entropic factor). Furthermore, the surface excess of methane shows a nonmonotonic dependence on pressure and shows negative values at high pressures in the $\mathrm{CH}_{4}+$ water system. ${ }^{47,48,69}$ As demonstrated above, the IFT generally increases with pressure for the $\mathrm{CH}_{4}+$ decane+water system under the studied conditions (see Fig. 3). This may suggest that the behavior of the IFT is dominated by the negative surface excess of decane (see eq. (9)).

\subsection{Decane+water system in the presence of $\mathrm{CO}_{2}$}

Fig. 5 shows the IFTs as obtained from the MD calculations (open symbols) and the corresponding theoretical results (lines) for the decane+water system in the presence of carbon dioxide (mole fraction of carbon dioxide in the decane $/ \mathrm{CO}_{2}$-rich phase $x_{\mathrm{CO}_{2}} \approx 0.2,0.5$, and 0.8$)$ at reservoir conditions. The simulated IFT values at different pressures were replotted as a function of temperature and mole fraction of carbon dioxide $x_{\mathrm{CO}_{2}}$ in Figures $\mathrm{S} 17$ and $\mathrm{S} 18$, respectively. It is seen that our simulation results are consistent with the theoretical predictions. Note that our results are in good qualitative agreement with the available experimental ${ }^{27}$ data (solid symbols). The overall absolute average deviation, for instance, between the experimental and theoretical IFT data was less than about $10 \%$. As in the case of the decane+water system, the IFT

almost linearly increases with pressure at low values of $x_{\mathrm{CO}_{2}}$, and the linear slope of the IFT versus pressure plot increases with temperature for the $\mathrm{CO}_{2}+$ decane+water 

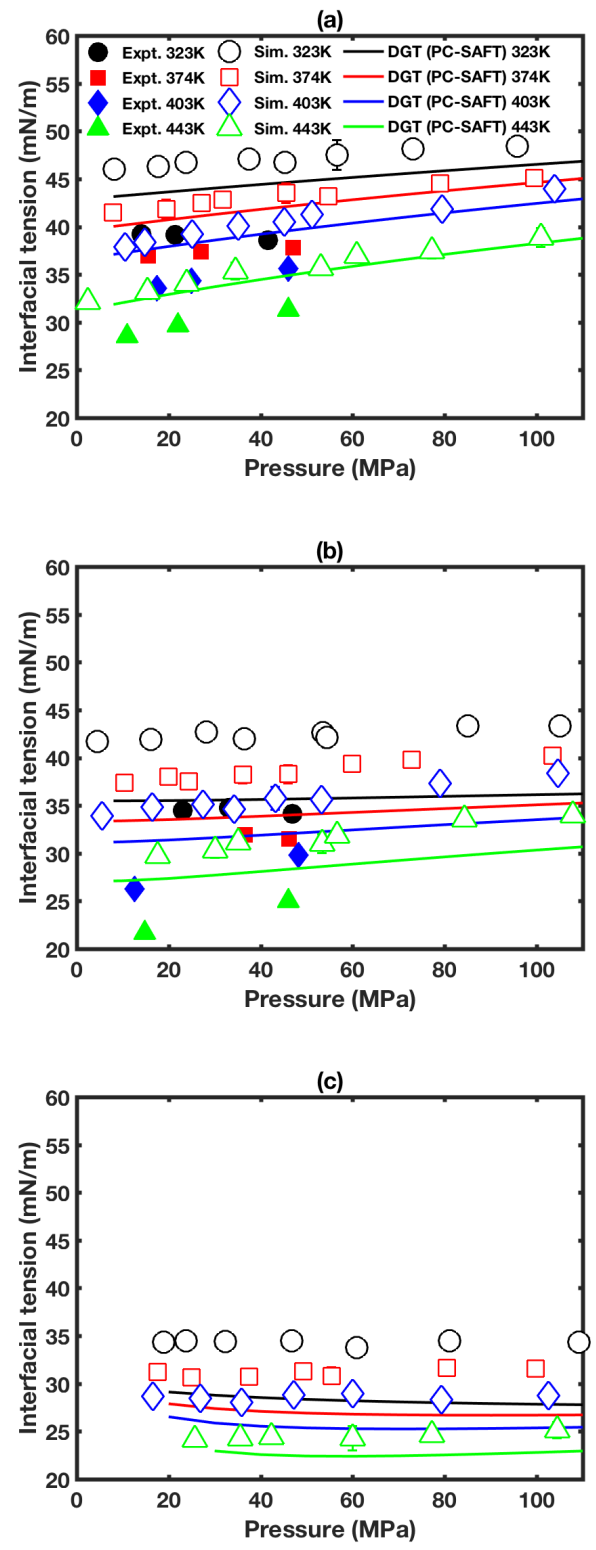

Figure 5: Interfacial tension as a function of pressure for the $\mathrm{CO}_{2}$ +decane+water system with (a) $x_{\mathrm{CO}_{2}} \approx 0.2$, (b) $x_{\mathrm{CO}_{2}} \approx 0.5$, and (c) $x_{\mathrm{CO}_{2}} \approx 0.8$. The open symbols represent the results from the MD simulations and the estimates obtained using DGT with the PC-SAFT EoS are shown as lines. The experimental results of Georgiadis et al. ${ }^{27}$ are shown as solid symbols. 
(a)

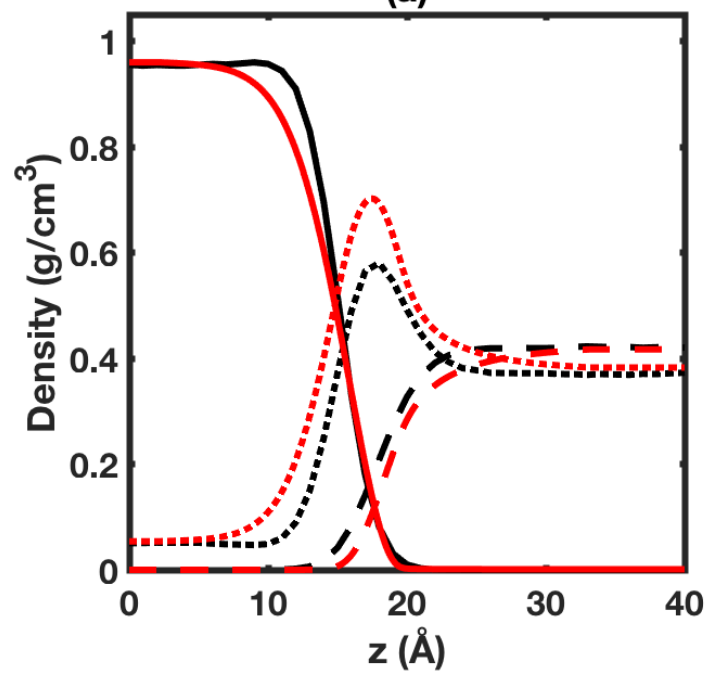

(c)

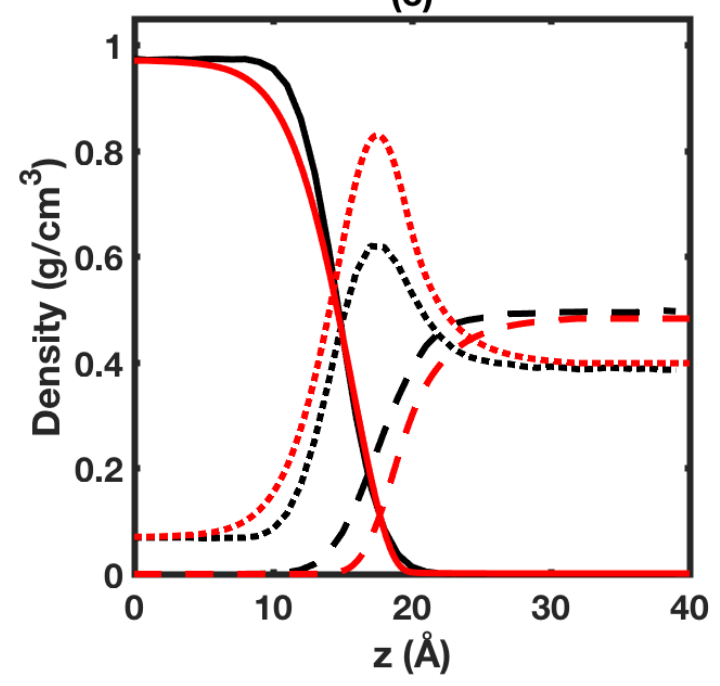

(b)

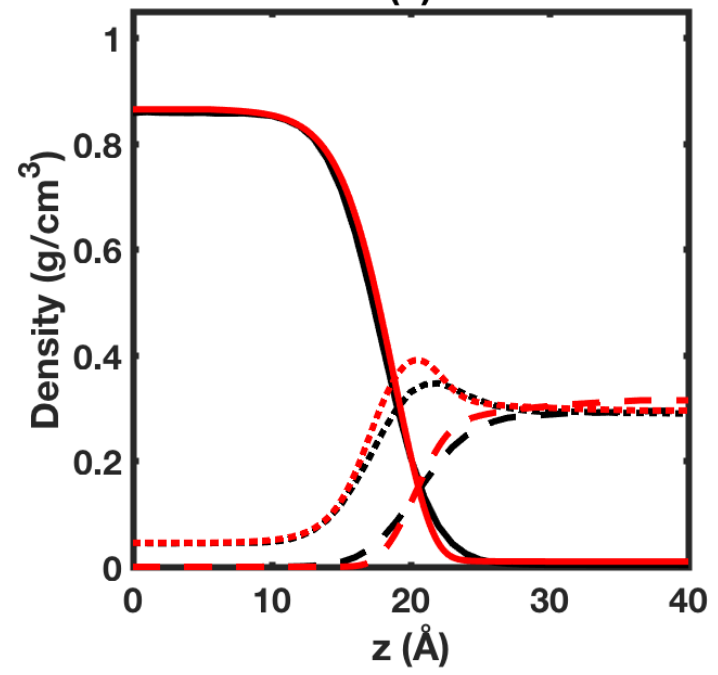

(d)

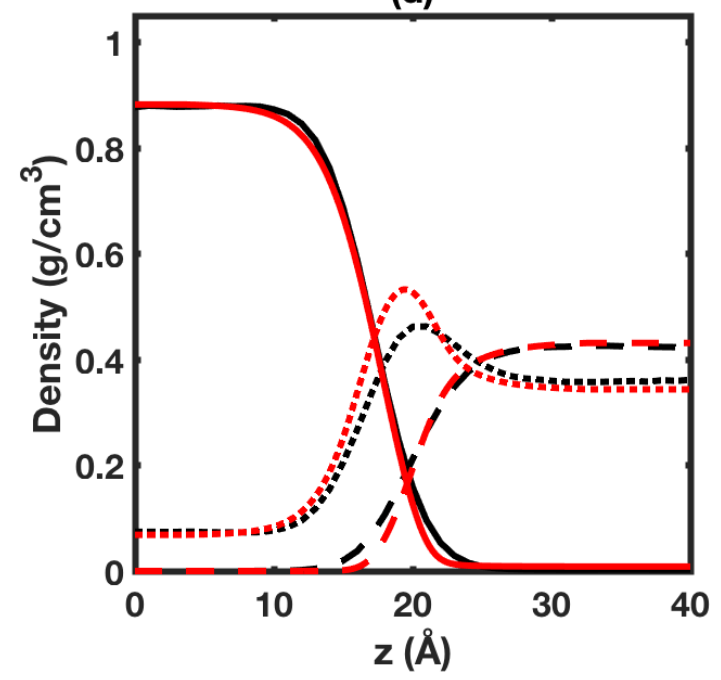

Figure 6: Equilibrium distributions of different species in the $\mathrm{CO}_{2}+$ decane+water system $\left(x_{\mathrm{CO}_{2}} \approx 0.8\right)$ at (a) $323 \mathrm{~K}$ and $30 \mathrm{MPa}$, (b) $443 \mathrm{~K}$ and $30 \mathrm{MPa}$, (c) $323 \mathrm{~K}$ and $100 \mathrm{MPa}$, and (d) $443 \mathrm{~K}$ and $100 \mathrm{MPa}$. The black and red colors represent MD simulation and DGT, respectively. The solid, dashed, and dotted lines denote water, decane, and carbon dioxide, respectively.

system. Also, the linear slope of the IFT versus pressure plot decreases with increasing mole fraction of carbon dioxide $x_{\mathrm{CO}_{2}}$. For instance, the simulated slope ( $T=443$ 
K) changes from about $0.07 \mathrm{mN} /(\mathrm{m} \mathrm{MPa})$ at $x_{\mathrm{CO}_{2}} \approx 0.2$ to $0.04 \mathrm{mN} /(\mathrm{m} \mathrm{MPa})$ at $x_{\mathrm{CO}_{2}} \approx 0.5$. The IFT is almost independent of pressure for the $\mathrm{CO}_{2}+$ decane+water system at high values of $x_{\mathrm{CO}_{2}}$. It is interesting to note that the IFT shows a nonmonotonic dependence on pressure in the $\mathrm{CO}_{2}+$ water system and, at low pressures, it decreases with pressure as discussed in previous studies. ${ }^{47,53,54}$ Also, for a given pressure, the IFT decreases almost linearly with increasing temperature and increasing mole fraction of carbon dioxide $x_{\mathrm{CO}_{2}}$. It can be seen that, independent of the mole fraction of $\mathrm{CO}_{2}$, the slope of the IFT versus temperature plot varies from about -0.09 to $-0.07 \mathrm{mN} /(\mathrm{m} \mathrm{K})$ in the pressure range $30-100 \mathrm{MPa}$ (see Figure S17). The slope of the IFT versus $\mathrm{CO}_{2}$ mole fraction plot is in the range of about -20 to $-15 \mathrm{mN} / \mathrm{m}$ (see Figure S18).

It is important to consider the atomic density profiles to gain more insights into the bulk and interfacial properties of the $\mathrm{CO}_{2}+$ decane+water system. For example, Fig. 6 provides the density profiles of carbon dioxide, decane, and water as predicted by $\mathrm{MD}$ and theoretical calculations for the $\mathrm{CO}_{2}+$ decane+water system $\left(x_{\mathrm{CO}_{2}} \approx 0.8\right)$. Also, Figures S19 and S20 provide these profiles at $x_{\mathrm{CO}_{2}} \approx 0.2$ and $x_{\mathrm{CO}_{2}} \approx 0.5$, respectively. An overall agreement between the simulation and theoretical results has been obtained. Here the shape of the density profiles of decane and water is, in general, similar to that observed for the decane+water system. In contrast to the behavior of the $\mathrm{CH}_{4}+$ decane+water system, no decane enrichment at the interface is obtained in the $\mathrm{CO}_{2}+$ decane+water system under the studied conditions, probably due to the stronger interaction of a water molecule with a $\mathrm{CO}_{2}$ molecule than with a decane molecule (simulated binding energy of the $\mathrm{CO}_{2}$-water dimer is about $-2.29 \mathrm{kcal} / \mathrm{mol}$ ). Notably, the density profiles display a systematic adsorption of carbon dioxide in the interface. We see that this local enrichment of carbon dioxide at the interface increases with increasing pressure and decreasing temperature. It is worth noting that, the local enrichment of $\mathrm{CO}_{2}$ shows a nonmonotonic dependence on pressure in the carbon dioxide+water system as discussed in previous studies. ${ }^{47,53,54}$ Our results also show that the enrichment of the interface by $\mathrm{CO}_{2}$ generally increases with increasing mole fraction 
of carbon dioxide $x_{\mathrm{CO}_{2}}$. Furthermore, Figures S21, S22, and S23 show our calculated solubilities of $\mathrm{CO}_{2}$ in the water-rich phase, decane in the water-rich phase, and water in the decane $/ \mathrm{CO}_{2}$-rich phase, respectively, under the studied conditions. Our results show that these solubilities are affected by pressure, temperature, and mole fraction of carbon dioxide $x_{\mathrm{CO}_{2}}$. Overall, the solubility behavior in the $\mathrm{CO}_{2}+$ decane+water system is similar to that observed for the $\mathrm{CH}_{4}+$ decane+water system. As an exception, decane solubility increases with pressure (see, e.g., Figure S22). We found that, at a fixed temperature and pressure, the density of the water-rich phase decreases as the values of $x_{\mathrm{CO}_{2}}$ /solubility of $\mathrm{CO}_{2}$ in the water-rich phase increases (see, e.g., Figure S21). Therefore, at high values of $x_{\mathrm{CO}_{2}}$, an increase in pressure may favor the solvation of decane in water outweighing any unfavorable entropic cost. Also, we find that the solubility of water increases with increasing mole fraction of carbon dioxide $x_{\mathrm{CO}_{2}}$ at all pressures due to the relatively strong $\mathrm{CO}_{2}$-water interactions. ${ }^{38-40}$

It is also important to consider the surface excess in order to quantify, for example, the local enrichment of carbon dioxide at the interface. Figures S24 and S25 provide the surface excess of carbon dioxide and decane, respectively, as calculated from simulations (symbols) and from theoretical modeling (solid lines) for the $\mathrm{CO}_{2}+$ decane+water system under the studied conditions. We see that our simulation results are qualitatively consistent with the theoretical calculations. Here we observe a negative surface excess for decane, similar to case of the decane+water system. The dependence of this surface excess of decane on pressure and temperature is also similar, in general, to the decane+water system. As expected, the surface excess of decane generally decreases with increasing mole fraction of carbon dioxide $x_{\mathrm{CO}_{2}}$. However, an opposite trend is observed at high values of $x_{\mathrm{CO}_{2}}$. Overall, these effects seem to be more pronounced at low pressures and high temperatures. This is consistent with the fact that, $\mathrm{CO}_{2}$ and decane are immiscible at low pressures and high temperatures. ${ }^{49}$ We also observe a positive surface excess for carbon dioxide. Our results show that the surface excess of $\mathrm{CO}_{2}$ increases with increasing pressure and decreasing temperature. In general, the surface excess of $\mathrm{CO}_{2}$ increases with increasing mole fraction of carbon dioxide $x_{\mathrm{CO}_{2}}$. 
(a)

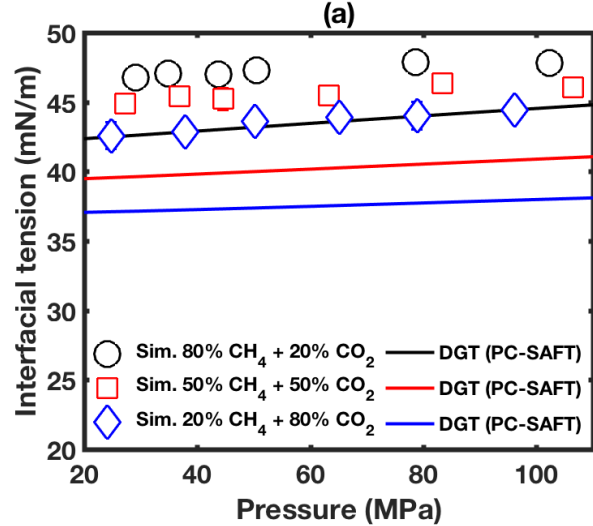

(c)

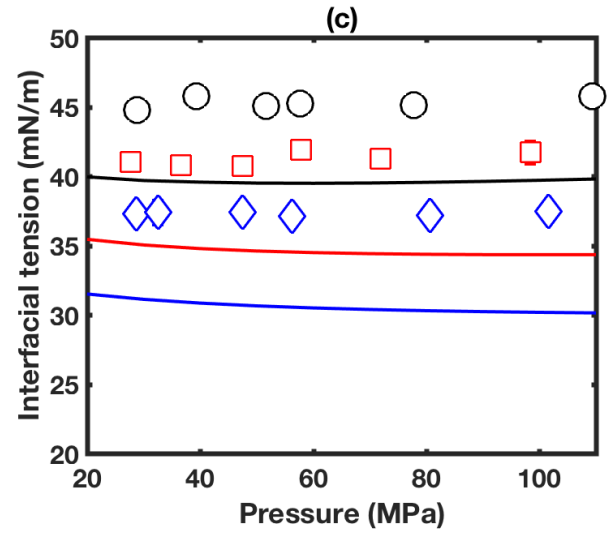

(b)

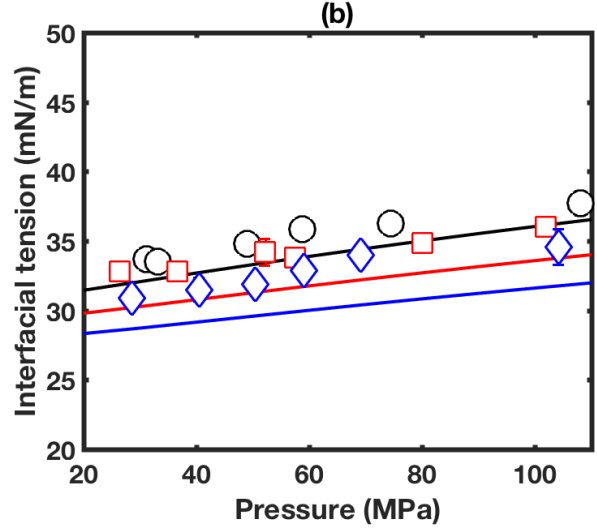

(d)

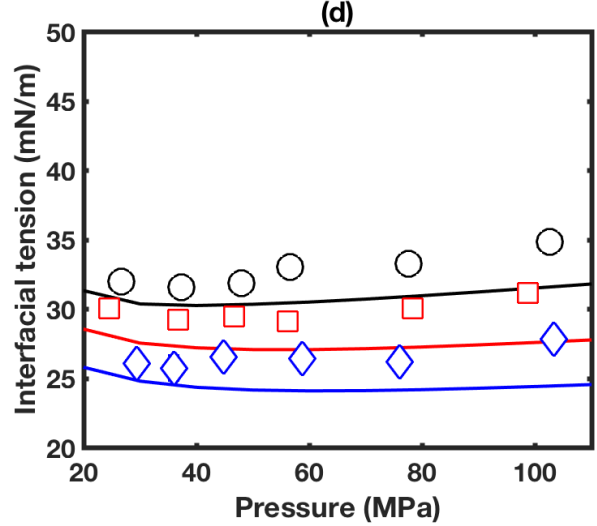

Figure 7: Interfacial tension as a function of pressure for the $\mathrm{CH}_{4}+\mathrm{CO}_{2}+$ decane+water system at (a) $323 \mathrm{~K}$ with $x_{\mathrm{CH}_{4}}+x_{\mathrm{CO}_{2}} \approx 0.5$, (b) $443 \mathrm{~K}$ with $x_{\mathrm{CH}_{4}}+x_{\mathrm{CO}_{2}} \approx 0.5$, (c) $323 \mathrm{~K}$ with $x_{\mathrm{CH}_{4}}+x_{\mathrm{CO}_{2}} \approx 0.8$, and (d) $443 \mathrm{~K}$ with $x_{\mathrm{CH}_{4}}+x_{\mathrm{CO}_{2}} \approx 0.8$. The symbols represent the results from the MD simulations and the estimates obtained using DGT with the PC-SAFT EoS are shown as lines.

As in the $\mathrm{CH}_{4}+$ decane+water case, the IFT generally increases with pressure for the $\mathrm{CO}_{2}+$ decane+water system under the studied conditions (see Fig. 5). This result may indicate that the behavior of the IFT is dominated by the negative surface excess of decane (see eq. (9)).

\subsection{Decane+water system in the presence of $\mathrm{CH}_{4}$ and $\mathrm{CO}_{2}$}

Fig. 7 provides the IFTs as obtained from the MD calculations (symbols) and the corresponding theoretical results (lines) for the decane+water system in the presence 
(a)

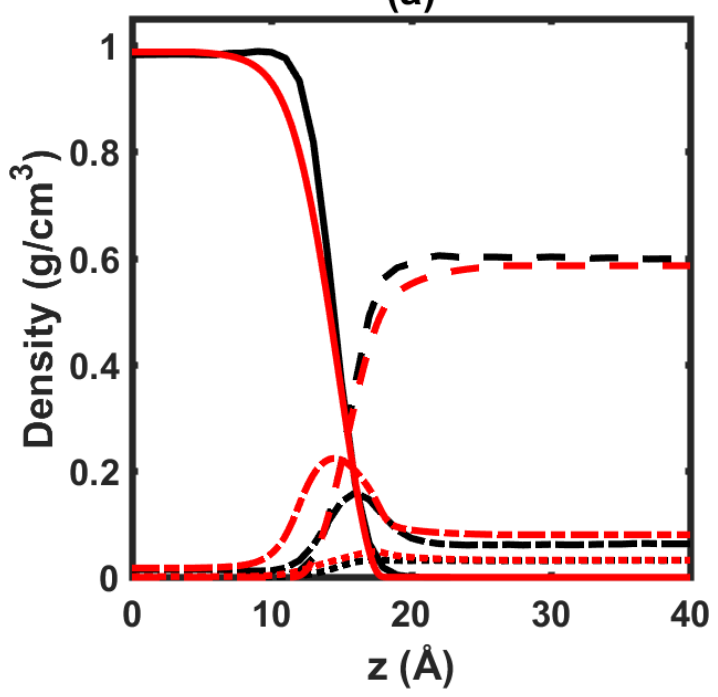

(c)

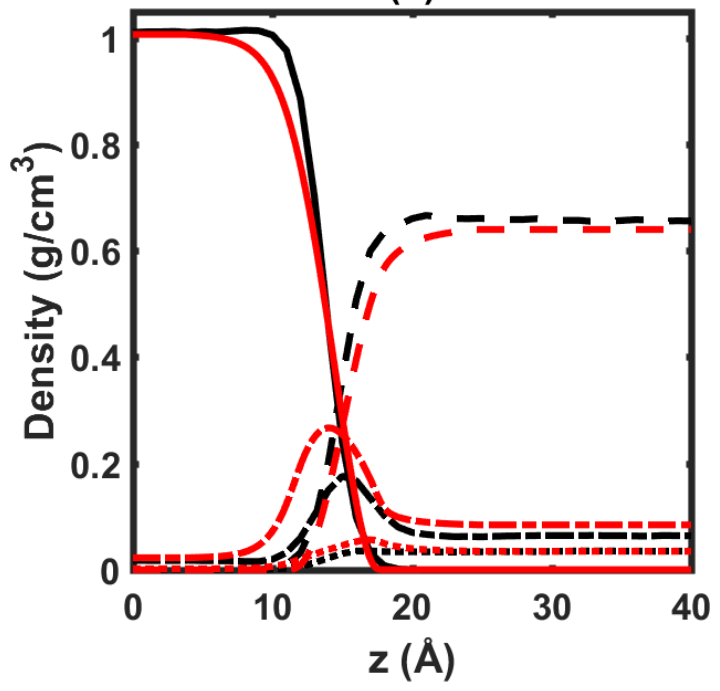

(b)

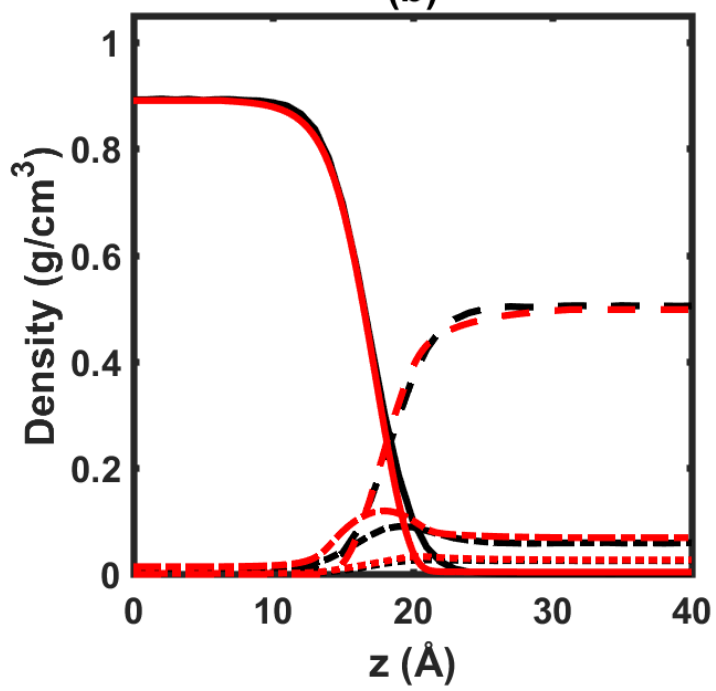

(d)

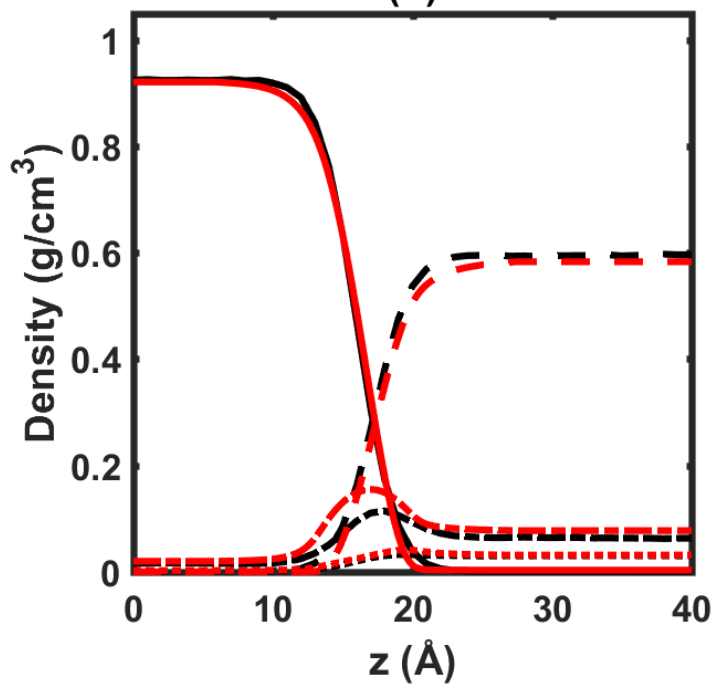

Figure 8: Equilibrium distributions of different species in the $\mathrm{CH}_{4}+\mathrm{CO}_{2}$ +decane+water system $\left(x_{\mathrm{CH}_{4}}=x_{\mathrm{CO}_{2}} \approx 0.25\right)$ at (a) $323 \mathrm{~K}$ and 30 $\mathrm{MPa}$, (b) $443 \mathrm{~K}$ and $30 \mathrm{MPa}$, (c) $323 \mathrm{~K}$ and $100 \mathrm{MPa}$, and (d) $443 \mathrm{~K}$ and $100 \mathrm{MPa}$. The black and red colors represent MD simulation and DGT, respectively. The solid, dashed, dotted, and dot-dashed lines denote water, decane, methane, and carbon dioxide, respectively.

of methane and carbon dioxide $\left(x_{\mathrm{CH}_{4}}+x_{\mathrm{CO}_{2}} \approx 0.5\right.$ and 0.8$)$ under geological conditions. The simulated IFT values at different pressures were replotted as a function of the mole 
fraction of carbon dioxide $x_{\mathrm{CO}_{2}}$ in Figure S26. It is seen that our simulation results are consistent with the theoretical predictions. Among all studied systems, the maximum difference between the simulated IFT values and the theoretical ones is found in the case of the water+decane system in the presence of $\mathrm{CO}_{2}\left(x_{\mathrm{CO}_{2}}=0.8\right)$ and at the lowest temperature (see, e.g., Fig. 5). For this case, the simulated values are higher by a factor of about 1.2 than the theoretical ones at all pressures. An important finding is that the presence of $\mathrm{CO}_{2}$ decreases the IFT of the $\mathrm{CH}_{4}+$ decane+water system. As in the binary and ternary cases discussed above, the IFT almost linearly increases with pressure for the $\mathrm{CH}_{4}+\mathrm{CO}_{2}+$ decane+water system at low values of $x_{\mathrm{CH}_{4}}+x_{\mathrm{CO}_{2}}$. The IFT is almost independent of pressure for the $\mathrm{CH}_{4}+\mathrm{CO}_{2}+$ decane+water system at high values of $x_{\mathrm{CH}_{4}}+x_{\mathrm{CO}_{2}}$. It is worth noting that, at low pressures, the IFT decreases with pressure in the $\mathrm{CH}_{4}+\mathrm{CO}_{2}+$ water system as discussed in our previous study. ${ }^{47}$ Also, the IFT decreases almost linearly with increasing mole fraction of carbon dioxide $x_{\mathrm{CO}_{2}}$. For instance, the simulated slope is in the range of about -18 to $-8 \mathrm{mN} / \mathrm{m}$ (see Figure S26).

Fig. 8 provides the density profiles of methane, carbon dioxide, decane, and water as predicted by $\mathrm{MD}$ and theoretical calculations for the $\mathrm{CH}_{4}+\mathrm{CO}_{2}+$ decane+water system $\left(x_{\mathrm{CH}_{4}}=x_{\mathrm{CO}_{2}} \approx 0.25\right)$. Also, Figures S27-S31 show these profiles at different mixture compositions. An overall agreement between the simulation and theoretical results has been obtained. Here the shape of the density profiles of the different species is similar to that observed for the $\mathrm{CH}_{4}+$ decane+water and $\mathrm{CO}_{2}+$ decane+water systems. As in the case of the ternary systems, we could observe the local enrichment of the interface by methane, carbon dioxide, and decane. Note that the enrichment of the interface by decane is observed only at high values of $x_{\mathrm{CH}_{4}}$. The results show the preferential dissolution in the water-rich phase and enrichment at the interface for $\mathrm{CO}_{2}$ in the $\mathrm{CH}_{4}+\mathrm{CO}_{2}+$ decane+water system. This indicates the preferential interaction of water with $\mathrm{CO}_{2}$ relative to methane and decane. Similar local accumulation of methane and carbon dioxide at the interface was also observed in the $\mathrm{CH}_{4}+\mathrm{CO}_{2}+$ water system as discussed in our previous study. ${ }^{47}$ Furthermore, Figures S32, S33, S34, and S35 
show our calculated solubilities of $\mathrm{CH}_{4}$ in the water-rich phase, $\mathrm{CO}_{2}$ in the water-rich phase, decane in the water-rich phase, and water in the decane $/ \mathrm{CH}_{4} / \mathrm{CO}_{2}$-rich phase, respectively, under the studied conditions. The overall dependence of the solubilities on pressure, temperature, and mole fractions is similar to that observed for the ternary systems. For example, as in the case of the ternary systems, the solubility of $\mathrm{CH}_{4}$ and $\mathrm{CO}_{2}$ increases with pressure, whereas the solubility of water shows an opposite trend.

Figures S36, S37, and S38 provide the surface excess of $\mathrm{CH}_{4}, \mathrm{CO}_{2}$, and decane, respectively, as calculated from simulations (symbols) and from theoretical modeling (solid lines) for the $\mathrm{CH}_{4}+\mathrm{CO}_{2}+$ decane+water system under the studied conditions. We see that our simulation results are qualitatively consistent with the theoretical calculations. The overall dependence of the surface excess on pressure, temperature, and mole fractions is also similar to that observed for the ternary systems. The strong preference of water for $\mathrm{CO}_{2}$ over $\mathrm{CH}_{4}$ may result in a relatively higher surface excess for $\mathrm{CO}_{2}$. Notably, we find a positive surface excess for decane and a negative surface excess for methane at high values of $x_{\mathrm{CH}_{4}}$. These effects seem to be more pronounced at low pressures and high temperatures. As in the binary and ternary cases, the IFT generally increases with pressure for the $\mathrm{CH}_{4}+\mathrm{CO}_{2}+$ decane+water system under the studied conditions (see Fig. 7). This may suggest that the behavior of the IFT is dominated by the negative surface excess of decane (see eq. (9)). The increasing contributions of the positive surface excesses of methane and/or $\mathrm{CO}_{2}$ may affect the above behavior at high mole fractions of $\mathrm{CH}_{4} / \mathrm{CO}_{2}$.

\subsection{Alternative theoretical model}

We also applied the cubic-plus-association (CPA) EoS to compute the bulk and interfacial properties of our mixtures. The details of the DGT with the bulk phase properties evaluated using the CPA EoS have been reported in our previous study. ${ }^{48}$ Additionally, the parameters to account for the interaction of decane with other species are given in Tables S5-S8. These parameters were obtained from literature ${ }^{83-85}$ and in the

absence of literature data, they were identified by fitting the experimental data. ${ }^{27,60,67}$ 
For example, Figure S39 shows the IFT of the decane+water system obtained using the DGT with the CPA EoS. The overall absolute average deviation between the experimental and theoretical IFT data was less than about 3.7\%. Figure S40 shows the calculated solubilities of water and decane at $0.1 \mathrm{MPa}$. A good quantitative agreement is obtained between the theoretical and experimental data. Furthermore, Figures S41 and $\mathrm{S} 42$ show the estimated IFTs of the $\mathrm{CH}_{4}+$ decane+water and $\mathrm{CO}_{2}$ +decane+water systems, respectively. It is seen that our theoretical results are qualitatively consistent with the experimental observations. For instance, for the $\mathrm{CO}_{2}+$ decane+water system, the overall absolute average deviation between the experimental and theoretical IFT data was less than about $12 \%$.

Furthermore, Figure S43 provides the estimated IFTs of the $\mathrm{CH}_{4}+\mathrm{CO}_{2}+$ decane+water system. Figure $\mathrm{S} 44$ shows the atomic density profiles for the $\mathrm{CH}_{4}+\mathrm{CO}_{2}+$ decane+water system. Figures S45, S46, S47, and S48 show our calculated solubility data for the $\mathrm{CH}_{4}+\mathrm{CO}_{2}+$ decane+water system. An overall agreement between the simulation and theoretical results has been obtained. Thus, we find that the overall performance of the PC-SAFT EoS and the CPA EoS is similar. Notably, the adsorption peak in the density profile of $\mathrm{CO}_{2}$ estimated using DGT with the CPA EoS has a slightly asymmetric shape across the interface (see, e.g., Figure S44). Also, the PC-SAFT EoS is relatively more sensitive to the change in the $k_{i j}$ value. For example, a $1 \%$ change in the $k_{i j}$ value results in about a $1 \%$ difference for the absolute average deviation between the experimental and theoretical (CPA EoS) solubility data of decane (see, e.g., Figure S40). By following the same procedure but using the PC-SAFT EoS, the difference is about $10 \%$.

The bulk and interfacial properties of the studied systems play a key role in the $\mathrm{CO}_{2}$-EOR projects. For instance, the oil recovery efficiency can be correlated to the IFT using the capillary number. ${ }^{18}$ The capillary number increases as IFT decreases and/or viscosity increases. A lower IFT is desirable for the $\mathrm{CO}_{2}$-EOR techniques which may help to improve oil recovery. Our results show that both methane and $\mathrm{CO}_{2}$ can lower the IFT between water and decane, and $\mathrm{CO}_{2}$ has a more significant effect 
than methane. This indicates that the advantage of $\mathrm{CO}_{2}$-EOR may be negatively affected by the presence of impurities such as methane. Note that an important part of the phase diagram of the $\mathrm{CO}_{2}+$ decane+water system is occupied by a region of three phase equilibria. ${ }^{30}$ As shown by us previously, ${ }^{49}$ at elevated pressures and temperatures, $\mathrm{CO}_{2}$ and decane become miscible, which may improve the flow properties of the highly viscous oil phase. The molecular simulation method is more time consuming than the DGT method. However, in comparison with DGT, properties such as the atomic radial distribution function, the chain size, and the molecular orientation can be readily calculated from the molecular simulations. ${ }^{37,49}$ These molecular details and the bulk and interfacial properties of the decane+brine system in the presence of gas mixtures will be presented in a future publication. Recently, we studied the bulk and interfacial properties of the $\mathrm{CH}_{4}+\mathrm{CO}_{2}+$ decane system below the minimum miscibility pressure. ${ }^{49}$ Here we extended this study to examine the bulk and interfacial properties of the $\mathrm{CH}_{4}+\mathrm{CO}_{2}+$ decane+water system. This may be important, e.g., for the better understanding of the WAG method used in the $\mathrm{CO}_{2}$-EOR projects. The phase behavior of the $\mathrm{CH}_{4}+\mathrm{CO}_{2}+$ decane system is significantly affected by the presence of water. For example, the $\mathrm{CH}_{4}+\mathrm{CO}_{2}+$ decane system is completely miscible at rather low pressures of a few hundred bars. ${ }^{49}$ However, we are able to explore the bulk and interfacial properties of the $\mathrm{CH}_{4}+\mathrm{CO}_{2}+$ decane+water system at much higher pressures due to the immiscibility between the water and the $\mathrm{CH}_{4}+\mathrm{CO}_{2}+$ decane phases.

In reality, $\mathrm{CO}_{2}$ may react with water to produce small amounts of, e.g., carbonic acid. For example, the simulated IFTs of the water $/ \mathrm{CO}_{2}$ system with and without reaction differed by less than about $6 \%$ at $333 \mathrm{~K} .{ }^{86}$ Such effects may be neglected, since the addition of decane decreases the solubility of $\mathrm{CO}_{2}$ in water (see, e.g., Fig. $\mathrm{S} 21)$. The most important finding of this study is that the presence of $\mathrm{CO}_{2}$ decreases the IFT of the $\mathrm{CH}_{4}+$ decane+water system. This may be explained by the preferential interaction of water with $\mathrm{CO}_{2}$ relative to $\mathrm{CH}_{4}$ and decane and, as a consequence, the preferential enrichment at the interface for $\mathrm{CO}_{2}$ in the $\mathrm{CH}_{4}+\mathrm{CO}_{2}+$ decane+water system. Interestingly by tuning, for example, the mole fraction $x_{\mathrm{CH}_{4}}+x_{\mathrm{CO}_{2}}$, we obtained 
an enrichment of decane at this interface. Additionally, the simulation studies were complemented by theoretical modeling and reasonable agreement is obtained.

The simulated binding energy of decane-water is about $-0.57,-0.67$, and -0.74 $\mathrm{kcal} / \mathrm{mol}$ when $k_{i j}^{\mathrm{LJ}}$ is equal to $0.9,1.0,1.1$, respectively. These values for $\mathrm{CO}_{2}$-water are about $-2.26,-2.27$, and $-2.29 \mathrm{kcal} / \mathrm{mol}$, respectively. The simulated binding energy of the $\mathrm{CO}_{2}$-water dimer is consistent with the value of about $-2.85 \mathrm{kcal} / \mathrm{mol}$ obtained from quantum chemical calculations. ${ }^{87}$ Furthermore, the simulated water-methane binding energy is about $-0.24 \mathrm{kcal} / \mathrm{mol}$ (about $-0.90 \mathrm{kcal} / \mathrm{mol}$ from quantum chemical calculations $\left.{ }^{88}\right)$. The difference may be due to the use of nonpolarizable models in our simulations. ${ }^{89}$ We see that the magnitude of binding energy increases with increasing $k_{i j}^{\mathrm{LJ}}$ indicating stronger dimer interactions, and that water interacts preferentially with $\mathrm{CO}_{2}$ than with decane.

Overall, for decane+water, $\mathrm{CO}_{2}+$ water and $\mathrm{CH}_{4}+$ water systems, our results of the IFTs were in good agreement with the experiments (see, e.g., Figs. 2 and S2). But for both $\mathrm{CH}_{4}$ +water and $\mathrm{CO}_{2}$ +water systems the IFTs obtained from theoretical calculations deviate from experiment at low temperatures (the theory overestimates the IFTs of the $\mathrm{CO}_{2}+$ water system also at very high temperatures, however, the maximum temperature studied was $443 \mathrm{~K}$ ). This is due to the fact that we employed a temperature-independent binary-interaction parameter $\beta_{i j}$, for simplicity and as in previous studies ${ }^{48,69}$ (see Tables S4 and S8). The simulated IFTs of the decane+water system in the presence of $\mathrm{CH}_{4}$ and/or $\mathrm{CO}_{2}$ are in reasonable agreement with the theoretical estimates except at low temperatures and high-pressures, probably because we used a temperature-independent (and also a pressure-independent) $\beta_{i j}$.

In our simulations, the factor contributing to the deficiencies in reproducing solubility may be the use of nonpolarizable models. Xue et al. ${ }^{52}$ improved the accuracy of both IFT and solubility with nonpolarizable models by adjusting the mixing parameters and they found that TIP4P is a useful candidate, though it is not as accurate as TIP4P/2005 in estimating the IFT. Also, the Exp-6 water model with modified crossinteraction parameters provided accurate results for the solubilities in the $\mathrm{CO}_{2}+$ water 
system. ${ }^{90}$ However, this model is not accurate for systems with added salt. ${ }^{91}$ The simulated IFTs for the $\mathrm{CH}_{4}+\mathrm{CO}_{2}+$ water system obtained using the flexible $\mathrm{F} 3 \mathrm{C}$ water model are in poor agreement with experiment. ${ }^{47}$ Furthermore, polarizable models provided accurate results for the solubilities in the $\mathrm{CO}_{2}+$ water and alkane+water systems. ${ }^{89}$ We hope to explore the effects of, e.g., polarizable models on the interfacial properties of the decane+water $+\mathrm{CH}_{4} / \mathrm{CO}_{2}$ system in a future study.

As shown in Figure S5, our results are in good agreement with the experimental bulk densities. Also, the bulk solubilities of decane in the water-rich phase and water in the decane-rich phase are rather small (see, e.g., Figure S6). Therefore, their contribution away from the interface (see, e.g., Figure S4) to the integral in eq. (10) (surface excess) is relatively negligible. For the decane+water system, the simulated surface excess is in reasonable agreement with the theoretical calculations, except at low temperatures (see Figure S7). This can be explained by noting that, in contrast to the theoretical prediction, oscillations are present near the interface for the simulated density profile of decane at low temperatures (see, e.g., Figure S4), which may be due to the finite size of the simulated system. ${ }^{81,82}$ As with the IFTs, the simulated surface excesses of the decane+water system in the presence of $\mathrm{CH}_{4}$ and/or $\mathrm{CO}_{2}$ are in reasonable agreement with the theoretical estimates except at low temperatures and high pressures, probably due to the use of a temperature-independent (and also a pressure-independent) $\beta_{i j}$ and/or finite size of the simulated system.

\section{Conclusions}

MD simulations were carried out to study the two-phase behavior of the n-decane+water system in the presence of $\mathrm{CH}_{4}, \mathrm{CO}_{2}$, and their mixture over broad ranges of temperature (323-443 K) and pressure (up to about $100 \mathrm{MPa}$ ). The simulation studies are complemented by theoretical modeling using the PC-SAFT EoS and density gradient theory. Our simulation and theoretical results for the IFT of the $\mathrm{CH}_{4}+$ decane+water and $\mathrm{CO}_{2}+$ decane+water systems are qualitatively consistent with the available exper- 
imental ${ }^{27,28}$ data. We find that the presence of $\mathrm{CH}_{4}$ and $\mathrm{CO}_{2}$ decreases the IFT of the decane+water system. The IFT increases with increasing pressure and decreasing temperature for the decane+water system. Generally, similar results are obtained in the presence of $\mathrm{CH}_{4}$ and $\mathrm{CO}_{2}$. The key finding from this work is that the presence of $\mathrm{CO}_{2}$ decreases the IFT of the $\mathrm{CH}_{4}+$ decane+water system.

We have compared the atomic density profiles obtained using molecular simulations and DGT, in all studied systems. An overall agreement between the simulation and theoretical results has been obtained. The local enrichment of $\mathrm{CH}_{4}$ and $\mathrm{CO}_{2}$ at the interface is usually observed in these systems. Another interesting finding is the preferential dissolution in the water-rich phase and accumulation at the interface for $\mathrm{CO}_{2}$ in the $\mathrm{CH}_{4}+\mathrm{CO}_{2}+$ decane+water system. This suggests an enhanced interaction between water and $\mathrm{CO}_{2}$ compared to the interactions between water and $\mathrm{CH}_{4} /$ decane. Interestingly, an enrichment of decane at the interface is observed at high mole fractions of $\mathrm{CH}_{4}$ in the $\mathrm{CH}_{4} /$ decane-rich or $\mathrm{CH}_{4} / \mathrm{CO}_{2} /$ decane-rich phase. Consistent with these results, the systems show in general a positive surface excess for $\mathrm{CH}_{4}$ and $\mathrm{CO}_{2}$ and a negative surface excess for decane. However, we found a positive surface excess for decane and a negative surface excess for methane at high values of $x_{\mathrm{CH}_{4}}$. Furthermore, we calculated the solubilities of $\mathrm{CH}_{4}, \mathrm{CO}_{2}$, and decane in the water-rich phase, and water in the decane $/ \mathrm{CH}_{4} / \mathrm{CO}_{2}$-rich phase. For example, we found that the solubility of $\mathrm{CH}_{4}$ and $\mathrm{CO}_{2}$ in the water-rich phase generally increases with increasing pressure and temperature in the studied systems. Finally, we demonstrated that the general performance of the PC-SAFT EoS and the CPA EoS is similar with respect to the evaluation of bulk and interfacial properties of the decane+water system in the presence of $\mathrm{CH}_{4}, \mathrm{CO}_{2}$, and their mixture.

\section{Acknowledgments}

This publication is based upon work supported by the King Abdullah University of Science and Technology (KAUST) Office of Sponsored Research (OSR) under Award No. OSR-2019-CRG8-4074. Y.Y., M.F.A.C.R., and A.K.N.N. would like to thank 
computational support from KAUST.

\section{Supporting Information}

Additional details of simulation analysis and theory are provided in the Supporting

Information. Tables S1-S4 and S5-S8 provide parameters for PC-SAFT/DGT and CPA/DGT theories, respectively. Figs. S1-S2 provide parameters for the extended Lorentz-Berthelot combining rule. Figs. S3-S7, S8-S16, S17-S25, S26-S38 provide IFT, solubility, denisty profiles, and surface excess for decane+water, $\mathrm{CH}_{4}+$ decane+water, $\mathrm{CO}_{2}+$ decane+water, and $\mathrm{CH}_{4}+\mathrm{CO}_{2}+$ decane+water systems, respectively. Figs. S39S48 provide the same data obtained using CPA/DGT theory. 


\section{References}

(1) Birol, F. CO2 emissions from fuel combustion Highlights. 2016

(2) Houghton, E. Climate change 1995: The science of climate change: contribution of working group I to the second assessment report of the Intergovernmental Panel on Climate Change; Cambridge University Press, 1996; Vol. 2

(3) Cox, P. M.; Betts, R. A.; Jones, C. D.; Spall, S. A.; Totterdell, I. J. Acceleration of global warming due to carbon-cycle feedbacks in a coupled climate model. Nature 2000, 408, 184

(4) Stocker, T. F.; Qin, D.; Plattner, G.-K.; Tignor, M.; Allen, S. K.; Boschung, J.; Nauels, A.; Xia, Y.; Bex, V.; Midgley, P. M., et al. Climate change 2013: The physical science basis. 2013

(5) Moore, J. C.; Gladstone, R.; Zwinger, T.; Wolovick, M. Geoengineer polar glaciers to slow sea-level rise. 2018

(6) Yang, H.; Xu, Z.; Fan, M.; Gupta, R.; Slimane, R. B.; Bland, A. E.; Wright, I. Progress in carbon dioxide separation and capture: A review. Journal of environmental sciences 2008, 20, 14-27

(7) Rangnekar, N.; Mittal, N.; Elyassi, B.; Caro, J.; Tsapatsis, M. Zeolite membranesa review and comparison with MOFs. Chemical Society Reviews 2015, 44, 71287154

(8) Sumida, K.; Rogow, D. L.; Mason, J. A.; McDonald, T. M.; Bloch, E. D.; Herm, Z. R.; Bae, T.-H.; Long, J. R. Carbon dioxide capture in metal-organic frameworks. Chemical reviews 2011, 112, 724-781

(9) Yampolskii, Y. Polymeric gas separation membranes. Macromolecules 2012, 45, $3298-3311$ 
(10) Kupgan, G.; Abbott, L. J.; Hart, K. E.; Colina, C. M. Modeling amorphous microporous polymers for CO2 capture and separations. Chemical reviews 2018, $118,5488-5538$

(11) Yang, Y.; Narayanan Nair, A. K.; Sun, S. Adsorption and diffusion of methane and carbon dioxide in amorphous regions of cross-linked polyethylene: a molecular simulation study. Industrial \&6 Engineering Chemistry Research 2019, 58, 84268436

(12) Kadoura, A.; Nair, A. K. N.; Sun, S. Adsorption of carbon dioxide, methane, and their mixture by montmorillonite in the presence of water. Microporous and Mesoporous Materials 2016, 225, 331-341

(13) Kadoura, A.; Narayanan Nair, A. K.; Sun, S. Molecular dynamics simulations of carbon dioxide, methane, and their mixture in montmorillonite clay hydrates. The Journal of Physical Chemistry C 2016, 120, 12517-12529

(14) Kadoura, A.; Narayanan Nair, A. K.; Sun, S. Molecular simulation study of montmorillonite in contact with variably wet supercritical carbon dioxide. The Journal of Physical Chemistry C 2017, 121, 6199-6208

(15) Langston, M.; Hoadley, S.; Young, D., et al. Definitive CO2 flooding response in the SACROC unit. SPE Enhanced Oil Recovery Symposium. 1988

(16) Blunt, M.; Fayers, F. J.; Orr Jr, F. M. Carbon dioxide in enhanced oil recovery. Energy Conversion and Management 1993, 34, 1197-1204

(17) Gozalpour, F.; Ren, S. R.; Tohidi, B. CO2 EOR and storage in oil reservoir. Oil 85 gas science and technology 2005, 60, 537-546

(18) Yang, D; Gu, Y. and Tontiwachwuthikul, P. Wettability determination of the reservoir brine- reservoir rock system with dissolution of $\mathrm{CO} 2$ at high pressures and elevated temperatures. Energy \& Fuels 2008, 22, 504-509 
(19) DiPietro, P.; Balash, P.; Wallace, M. A note on sources of CO2 supply for enhanced-oil-recovery operations. SPE Economics 8 Management 2012, 12, $1652-1654$

(20) Enick, R. M.; Olsen, D. K. Mobility and Conformance Control for Carbon Dioxide Enhanced Oil Recovery (CO2-EOR) via Thickeners, Foams, and Gels-A Detailed Literature Review of 40 Years of Research. Contract DE-FE0004003. Activity 2012, 4003

(21) Dai, Z.; Viswanathan, H.; Middleton, R.; Pan, F.; Ampomah, W.; Yang, C.; Jia, W.; Xiao, T.; Lee, S.-Y.; McPherson, B., et al. CO2 accounting and risk analysis for CO2 sequestration at enhanced oil recovery sites. Environmental science \& technology 2016, 50, 7546-7554

(22) None, N. Annual Energy Outlook 2016 With Projections to 2040; 2016

(23) Olajire, A. A. CO2 capture and separation technologies for end-of-pipe applications-a review. Energy 2010, 35, 2610-2628

(24) Li, H.; Jakobsen, J. P.; Wilhelmsen, Ø.; Yan, J. PVTxy properties of CO2 mixtures relevant for $\mathrm{CO} 2$ capture, transport and storage: Review of available experimental data and theoretical models. Applied Energy 2011, 88, 3567-3579

(25) Blanco, S. T.; Rivas, C.; Fernandez, J.; Artal, M.; Velasco, I. Influence of methane in CO2 transport and storage for CCS technology. Environmental science $\&$ technology 2012, 46, 13016-13023

(26) Pereira, L. M. C.; Chapoy, A.; Tohidi, B., et al. Vapor-liquid and liquid-liquid interfacial tension of water and hydrocarbon systems at representative reservoir conditions: Experimental and modelling results. SPE Annual Technical Conference and Exhibition. 2014 
(27) Georgiadis, A.; Maitland, G.; Trusler, J. M.; Bismarck, A. Interfacial tension measurements of the $(\mathrm{H} 2 \mathrm{O}+\mathrm{n}$-decane+ $\mathrm{CO} 2)$ ternary system at elevated pressures and temperatures. Journal of Chemical \&f Engineering Data 2011, 56, 4900-4908

(28) Jennings Jr, H. Y.; Newman, G. H., et al. The effect of temperature and pressure on the interfacial tension of water against methane-normal decane mixtures. Society of petroleum engineers Journal 1971, 11, 171-175

(29) Sun, C.-Y.; Chen, G.-J. Measurement of interfacial tension for the CO2 injected crude oil+ reservoir water system. Journal of Chemical $\&$ Engineering Data 2005, $50,936-938$

(30) Forte, E.; Galindo, A.; Trusler, J. M. Experimental and molecular modeling study of the three-phase behavior of (n-decane+ carbon dioxide+ water) at reservoir conditions. The Journal of Physical Chemistry B 2011, 115, 14591-14609

(31) Gil, L.; Avila, S.; García-Giménez, P.; Blanco, S.; Berro, C.; Otin, S.; Velasco, I. Dew points of binary propane or n-butane+ carbon dioxide, ternary propane or n-butane + carbon dioxide + water, and quaternary propane or n-butane + carbon dioxide+ water + methanol mixtures: Measurement and modeling. Industrial $\&$ engineering chemistry research 2006, 45, 3974-3980

(32) Al Ghafri, S. Z.; Forte, E.; Galindo, A.; Maitland, G. C.; Trusler, J. M. Experimental and modeling study of the phase behavior of (heptane + carbon dioxide+ water) mixtures. Journal of Chemical \& Engineering Data 2015, 60, 3670-3681

(33) Brunner, G.; Teich, J.; Dohrn, R. Phase equilibria in systems containing hydrogen, carbon dioxide, water and hydrocarbons. Fluid Phase Equilibria 1994, 100, 253268

(34) Yang, D.; Tontiwachwuthikul, P.; Gu, Y. Interfacial tensions of the crude oil+ reservoir brine+ CO2 systems at pressures up to $31 \mathrm{MPa}$ and temperatures of 27 C and 58 C. Journal of chemical \& engineering data 2005, 50, 1242-1249 
(35) Bahramian, A.; Danesh, A.; Gozalpour, F.; Tohidi, B.; Todd, A. Vapour-liquid interfacial tension of water and hydrocarbon mixture at high pressure and high temperature conditions. Fluid phase equilibria 2007, 252, 66-73

(36) Kodera, M.; Watanabe, K.; Lassiège, M.; Alavi, S.; Ohmura, R. Interfacial tension between decane saturated with methane and water from $283.2 \mathrm{~K}$ to $298.2 \mathrm{~K}$ under pressures upto $10 \mathrm{MPa}$. Journal of Industrial and Engineering Chemistry 2020, $81,360-366$

(37) Zhao, L.; Tao, L.; Lin, S. Molecular dynamics characterizations of the supercritical CO2-mediated hexane-brine interface. Industrial $\&$ Engineering Chemistry Research 2015, 54, 2489-2496

(38) Zhang, J.; Dong, Z.; Zhang, Y.; Wang, M.; Yan, Y. Effects of the methane content on the water-oil interface: insights from the molecular level. Energy $\&$ fuels 2017, 31, 7026-7032

(39) Liu, B.; Shi, J.; Wang, M.; Zhang, J.; Sun, B.; Shen, Y.; Sun, X. Reduction in interfacial tension of water-oil interface by supercritical CO2 in enhanced oil recovery processes studied with molecular dynamics simulation. The Journal of Supercritical Fluids 2016, 111, 171-178

(40) Mohammed, S.; Mansoori, G. A. The role of supercritical/dense CO2 gas in altering aqueous/oil interfacial properties: a molecular dynamics study. Energy Ef fuels 2018, 32, 2095-2103

(41) Mohammed, S.; Mansoori, G. A. Effect of CO2 on the interfacial and transport properties of water/binary and asphaltenic oils: insights from molecular dynamics. Energy \&f fuels 2018, 32, 5409-5417

(42) Kumar, N. A.; Seidel, C. Polyelectrolyte brushes with added salt. Macromolecules 2005, 38, 9341-9350 
(43) Kumar, N. A.; Ganesan, V. Communication: Self-assembly of semiflexible-flexible block copolymers. 2012

(44) Stukalin, E. B.; Cai, L.-H.; Kumar, N. A.; Leibler, L.; Rubinstein, M. Self-healing of unentangled polymer networks with reversible bonds. Macromolecules 2013, $46,7525-7541$

(45) Narayanan Nair, A. K.; Martinez Jimenez, A.; Sun, S. Complexation behavior of polyelectrolytes and polyampholytes. The Journal of Physical Chemistry B 2017, 121, 7987-7998

(46) Li, Y.; Narayanan Nair, A. K.; Kadoura, A.; Yang, Y.; Sun, S. Molecular simulation study of montmorillonite in contact with water. Industrial \& Engineering Chemistry Research 2019, 58, 1396-1403

(47) Yang, Y.; Narayanan Nair, A. K.; Sun, S. Molecular dynamics simulation study of carbon dioxide, methane, and their mixture in the presence of brine. The Journal of Physical Chemistry B 2017, 121, 9688-9698

(48) Yang, Y.; Che Ruslan, M. F. A.; Narayanan Nair, A. K.; Sun, S. Effect of ion valency on the properties of the carbon dioxide-methane-brine system. The Journal of Physical Chemistry B 2019, 123, 2719-2727

(49) Choudhary, N.; Nair, A. K. N.; Ruslan, M. F. A. C.; Sun, S. Bulk and interfacial properties of decane in the presence of carbon dioxide, methane, and their mixture. Scientific Reports 2019, 9, 1-10

(50) Plimpton, S. Fast parallel algorithms for short-range molecular dynamics; 1993

(51) Martin, M. G.; Siepmann, J. I. Transferable potentials for phase equilibria. 1. United-atom description of n-alkanes. The Journal of Physical Chemistry B 1998, 102, 2569-2577 
(52) Xue, B.; Harwood, D. B.; Chen, J. L.; Siepmann, J. I. Monte Carlo Simulations of Fluid Phase Equilibria and Interfacial Properties for Water/Alkane Mixtures: An Assessment of Nonpolarizable Water Models and of Departures from the LorentzBerthelot Combining Rules. Journal of Chemical 85 Engineering Data 2018, 63, $4256-4268$

(53) Nielsen, L. C.; Bourg, I. C.; Sposito, G. Predicting CO2-water interfacial tension under pressure and temperature conditions of geologic CO2 storage. Geochimica et Cosmochimica Acta 2012, 81, 28-38

(54) Garrido, J. M.; Quinteros-Lama, H.; Miguez, J. M.; Blas, F. J.; Piñeiro, M. M. On the Physical Insight into the Barotropic Effect in the Interfacial Behavior for the H2O+ CO2 Mixture. The Journal of Physical Chemistry C 2019, 123, $28123-28130$

(55) Gross, J.; Sadowski, G. Perturbed-chain SAFT: An equation of state based on a perturbation theory for chain molecules. Industrial $\&$ engineering chemistry research 2001, 40, 1244-1260

(56) Gross, J.; Sadowski, G. Application of the perturbed-chain SAFT equation of state to associating systems. Industrial $\&$ engineering chemistry research 2002 , $41,5510-5515$

(57) Kontogeorgis, G. M.; Yakoumis, I. V.; Meijer, H.; Hendriks, E.; Moorwood, T. Multicomponent phase equilibrium calculations for water-methanol-alkane mixtures. Fluid Phase Equilibria 1999, 158, 201-209

(58) Tsivintzelis, I.; Kontogeorgis, G. M.; Michelsen, M. L.; Stenby, E. H. Modeling phase equilibria for acid gas mixtures using the CPA equation of state. Part II: Binary mixtures with CO2. Fluid Phase Equilibria 2011, 306, 38-56

(59) Diamantonis, N. I.; Economou, I. G. Evaluation of statistical associating fluid theory (SAFT) and perturbed chain-SAFT equations of state for the calculation 
of thermodynamic derivative properties of fluids related to carbon capture and sequestration. Energy \& Fuels 2011, 25, 3334-3343

(60) Maczyński, A.; Wiśniewska-Gocłowska, B.; Goral, M. Recommended liquid-liquid equilibrium data. Part 1. Binary alkane-water systems. Journal of physical and chemical reference data 2004, 33, 549-577

(61) Hou, S.-X.; Maitland, G. C.; Trusler, J. M. Measurement and modeling of the phase behavior of the (carbon dioxide+ water) mixture at temperatures from 298.15 K to 448.15 K. The Journal of Supercritical Fluids 2013, 73, 87-96

(62) Chapoy, A.; Mohammadi, A. H.; Richon, D.; Tohidi, B. Gas solubility measurement and modeling for methane-water and methane-ethane-n-butane-water systems at low temperature conditions. Fluid phase equilibria 2004, 220, 111-119

(63) Culberson, O.; McKetta Jr, J., et al. Phase equilibria in hydrocarbon-water systems III-the solubility of methane in water at pressures to 10,000 psia. Journal of Petroleum Technology 1951, 3, 223-226

(64) Davis, H.; Scriven, L. Stress and structure in fluid interfaces. Adv. Chem. Phys 1982, 49, 357-454

(65) Davis, H. T. Statistical mechanics of phases, interfaces, and thin films; VCH New York, 1996

(66) Mairhofer, J.; Gross, J. Modeling properties of the one-dimensional vapor-liquid interface: Application of classical density functional and density gradient theory. Fluid Phase Equilibria 2018, 458, 243-252

(67) NIST chemistry WebBook, NIST standard reference database number 69 . http://webbook.nist.gov/

(68) Pereira, L. M.; Chapoy, A.; Burgass, R.; Oliveira, M. B.; Coutinho, J. A.; Tohidi, B. Study of the impact of high temperatures and pressures on the equilibrium 
densities and interfacial tension of the carbon dioxide/water system. The Journal of Chemical Thermodynamics 2016, 93, 404-415

(69) Kashefi, K.; Pereira, L. M.; Chapoy, A.; Burgass, R.; Tohidi, B. Measurement and modelling of interfacial tension in methane/water and methane/brine systems at reservoir conditions. Fluid Phase Equilibria 2016, 409, 301-311

(70) Michaels, A.; Hauser, E. Interfacial tension at elevated pressure and temperature. II. Interfacial properties of hydrocarbon-water systems. The Journal of Physical Chemistry 1951, 55, 408-421

(71) Jennings Jr, H. Y. The effect of temperature and pressure on the interfacial tension of benzene-water and normal decane-water. Journal of colloid and interface science 1967, 24, 323-329

(72) Cai, B.-Y.; Yang, J.-T.; Guo, T.-M. Interfacial tension of hydrocarbon+ water/brine systems under high pressure. Journal of chemical $\&$ engineering data 1996, 41, 493-496

(73) Zeppieri, S.; Rodríguez, J.; López de Ramos, A. Interfacial tension of alkane+ water systems. Journal of Chemical \& Engineering Data 2001, 46, 1086-1088

(74) Goebel, A.; Lunkenheimer, K. Interfacial tension of the water/n-alkane interface. Langmuir 1997, 13, 369-372

(75) Wang, L.; Yang, J.; Mendenhall, J. D.; Cristancho, D. E.; Dowdle, J. R. An interfacial statistical associating fluid theory (iSAFT) approach for surface/interfacial tension predictions. Fluid Phase Equilibria 2018, 476, 193-201

(76) Medeiros, M. Liquid-liquid interfacial tensions of binary water-hydrocarbons mixtures via gradient theory and CPA equation of state. Fluid Phase Equilibria 2015, 392, $65-73$ 
(77) Mu, X.; Xi, S.; Alpak, F. O.; Chapman, W. G. Modified Density Gradient Theory for Surfactant Molecules Applied to Oil/Water Interfaces. Industrial $\& 3$ Engineering Chemistry Research 2018, 57, 7643-7654

(78) Papavasileiou, K. D.; Moultos, O. A.; Economou, I. G. Predictions of water/oil interfacial tension at elevated temperatures and pressures: A molecular dynamics simulation study with biomolecular force fields. Fluid Phase Equilibria 2018, 476, $30-38$

(79) Chen, J. L.; Xue, B.; Harwood, D. B.; Chen, Q. P.; Peters, C. J.; Siepmann, J. I. A Monte Carlo simulation study of the interfacial tension for water/oil mixtures at elevated temperatures and pressures: Water/n-dodecane, water/toluene, and water/(n-dodecane+ toluene). Fluid Phase Equilibria 2018, 476, 16-24

(80) Herdes, C.; Ervik, A.; Mejía, A.; Müller, E. A. Prediction of the water/oil interfacial tension from molecular simulations using the coarse-grained SAFT- $\gamma$ Mie force field. Fluid Phase Equilibria 2018, 476, 9-15

(81) Wick, C. D.; Chang, T.-M.; Slocum, J. A.; Cummings, O. T. Computational investigation of the n-alkane/water interface with many-body potentials: the effect of chain length and ion distributions. The Journal of Physical Chemistry C 2011, $116,783-790$

(82) Cummings, O. T.; Wick, C. D. Computational study on the effect of alkyl chain length on alkane-water interfacial width. Chemical Physics Letters 2013, 556, 65-69

(83) Yakoumis, I. V.; Kontogeorgis, G. M.; Voutsas, E. C.; Tassios, D. P. Vapor-liquid equilibria for alcoholhydrocarbon systems using the CPA Equation of state. Fluid Phase Equilibria 1997, 130, 31-47

(84) Bjørner, M. G.; Kontogeorgis, G. M. Modeling derivative properties and binary 
mixtures with CO2 using the CPA and the quadrupolar CPA equations of state. Fluid Phase Equilibria 2016, 408, 151-169

(85) Riaz, M.; Yussuf, M. A.; Kontogeorgis, G. M.; Stenby, E. H.; Yan, W.; Solbraa, E. Distribution of MEG and methanol in well-defined hydrocarbon and water systems: Experimental measurement and modeling using the CPA EoS. Fluid phase equilibria 2013, 337, 298-310

(86) Javanbakht, G.; Sedghi, M.; Welch, W.; Goual, L. Molecular dynamics simulations of $\mathrm{CO} 2 /$ water/quartz interfacial properties: impact of $\mathrm{CO} 2$ dissolution in water. Langmuir 2015, 31, 5812-5819

(87) Abashkin, Y.; Mele, F.; Russo, N.; Toscano, M. Density functional treatment of water-carbon dioxide van der waals complex. International journal of quantum chemistry 1994, 52, 1011-1015

(88) Cao, Z.; Tester, J. W.; Trout, B. L. Computation of the methane-water potential energy hypersurface via ab initio methods. The Journal of chemical physics 2001, $115,2550-2559$

(89) Jiang, H.; Economou, I. G.; Panagiotopoulos, A. Z. Phase equilibria of water/CO2 and water/n-alkane mixtures from polarizable models. The Journal of Physical Chemistry B 2017, 121, 1386-1395

(90) Orozco, G. A.; Economou, I. G.; Panagiotopoulos, A. Z. Optimization of intermolecular potential parameters for the $\mathrm{CO} 2 / \mathrm{H} 2 \mathrm{O}$ mixture. The Journal of Physical Chemistry B 2014, 118, 11504-11511

(91) Orozco, G. A.; Moultos, O. A.; Jiang, H.; Economou, I. G.; Panagiotopoulos, A. Z. Molecular simulation of thermodynamic and transport properties for the $\mathrm{H} 2 \mathrm{O}+$ $\mathrm{NaCl}$ system. The Journal of Chemical Physics 2014, 141, 234507 
Table 1: Number of molecules used in MD simulations.

\begin{tabular}{|c|c|c|c|c|}
\hline System & Water no. & Decane no. & $\mathrm{CH}_{4}$ no. & $\mathrm{CO}_{2}$ no. \\
\hline Water + Decane & 2048 & 200 & - & - \\
\hline Water $+80 \%$ Decane $+20 \% \mathrm{CH}_{4}$ & 2048 & 200 & 50 & - \\
\hline Water $+50 \%$ Decane $+50 \% \mathrm{CH}_{4}$ & 2048 & 200 & 200 & - \\
\hline Water $+20 \%$ Decane $+80 \% \mathrm{CH}_{4}$ & 2048 & 120 & 480 & - \\
\hline Water $+80 \%$ Decane $+20 \% \mathrm{CO}_{2}$ & 2048 & 200 & - & 50 \\
\hline Water $+50 \%$ Decane $+50 \% \mathrm{CO}_{2}$ & 2048 & 200 & - & 200 \\
\hline Water $+20 \%$ Decane $+80 \% \mathrm{CO}_{2}$ & 2048 & 120 & - & 480 \\
\hline Water $+50 \%$ Decane $+10 \% \mathrm{CH}_{4}+40 \% \mathrm{CO}_{2}$ & 2048 & 200 & 40 & 160 \\
\hline Water $+50 \%$ Decane $+25 \% \mathrm{CH}_{4}+25 \% \mathrm{CO}_{2}$ & 2048 & 200 & 100 & 100 \\
\hline Water $+50 \%$ Decane $+40 \% \mathrm{CH}_{4}+10 \% \mathrm{CO}_{2}$ & 2048 & 200 & 160 & 40 \\
\hline Water $+20 \%$ Decane $+16 \% \mathrm{CH}_{4}+64 \% \mathrm{CO}_{2}$ & 2048 & 125 & 100 & 400 \\
\hline Water $+20 \%$ Decane $+40 \% \mathrm{CH}_{4}+40 \% \mathrm{CO}_{2}$ & 2048 & 125 & 250 & 250 \\
\hline Water $+20 \%$ Decane $+64 \% \mathrm{CH}_{4}+16 \% \mathrm{CO}_{2}$ & 2048 & 125 & 400 & 100 \\
\hline
\end{tabular}



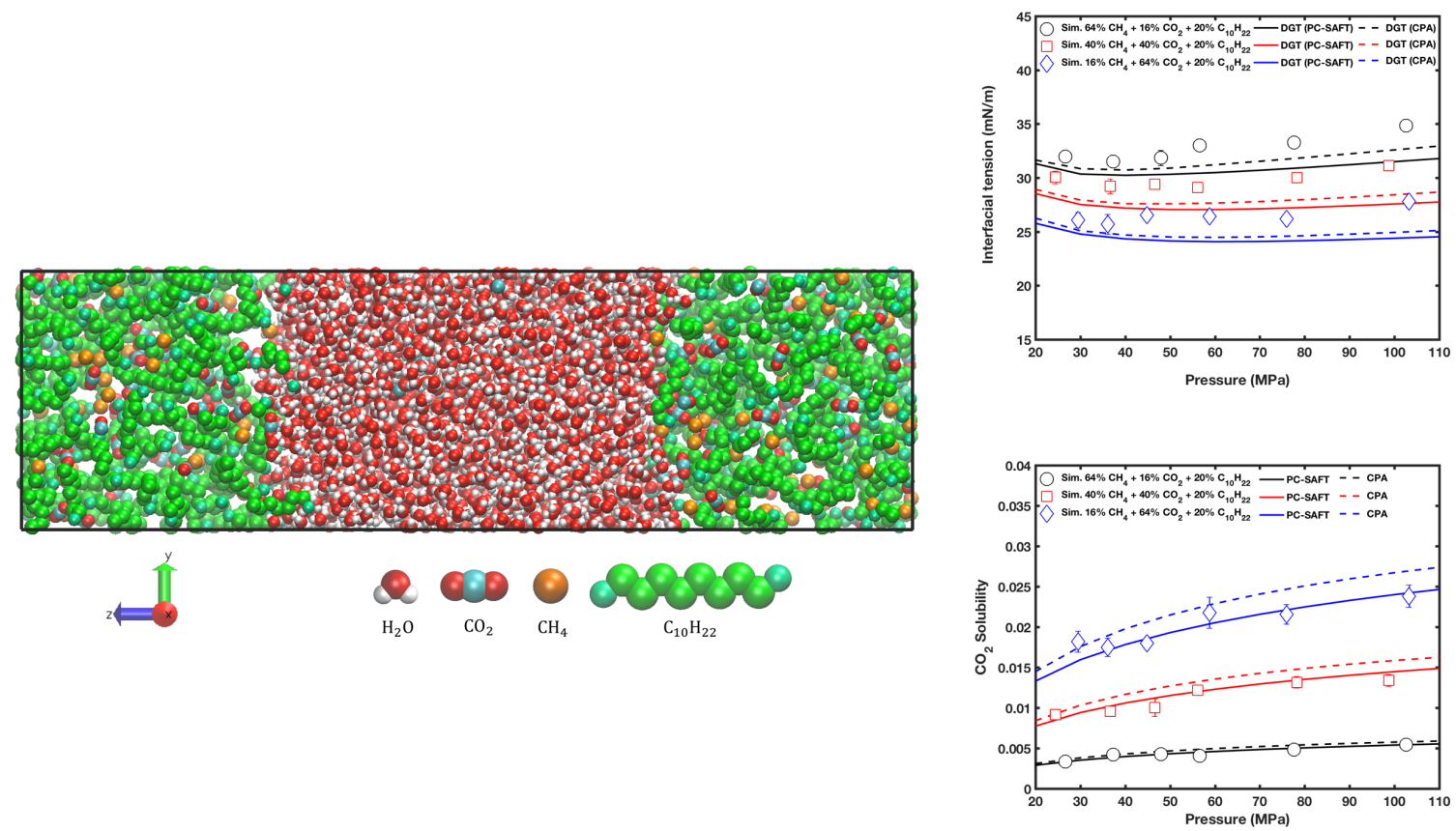

TOC Graphic 